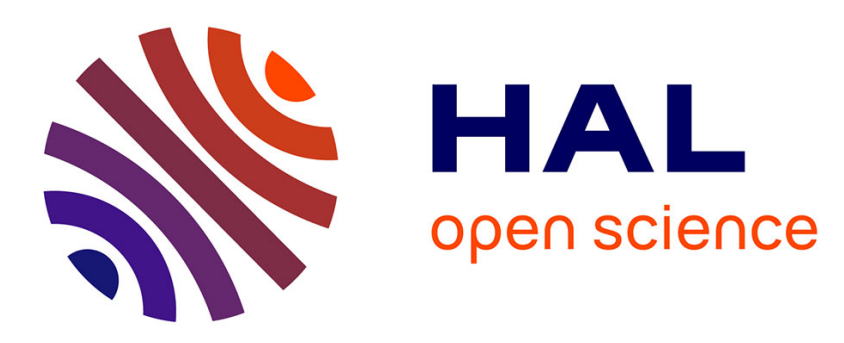

\title{
Microstructural analysis of nitrogen-doped char by Raman spectroscopy: Raman shift analysis from first principles
}

Michael Ayiania, Elsa Weiss-Hortala, Matthew Smith, Jean-Sabin Mcewen, Manuel Garcia-Perez

\section{To cite this version:}

Michael Ayiania, Elsa Weiss-Hortala, Matthew Smith, Jean-Sabin Mcewen, Manuel Garcia-Perez. Microstructural analysis of nitrogen-doped char by Raman spectroscopy: Raman shift analysis from first principles. Carbon, 2020, 167, pp.559-574. 10.1016/j.carbon.2020.05.055 . hal-02638698

\section{HAL Id: hal-02638698 https://imt-mines-albi.hal.science/hal-02638698}

Submitted on 16 Jul 2020

HAL is a multi-disciplinary open access archive for the deposit and dissemination of scientific research documents, whether they are published or not. The documents may come from teaching and research institutions in France or abroad, or from public or private research centers.
L'archive ouverte pluridisciplinaire HAL, est destinée au dépôt et à la diffusion de documents scientifiques de niveau recherche, publiés ou non, émanant des établissements d'enseignement et de recherche français ou étrangers, des laboratoires publics ou privés. 


\title{
Microstructural analysis of nitrogen-doped char by Raman spectroscopy: Raman shift analysis from first principles
}

\author{
Michael Ayiania a , Elsa Weiss-Hortala ${ }^{\mathrm{b}}$, Matthew Smith a, c, \\ Jean-Sabin McEwen ${ }^{\mathrm{a}, \mathrm{c}, \mathrm{d}, \mathrm{e}, \mathrm{f}, * *}$, Manuel Garcia-Perez ${ }^{\mathrm{a}, \mathrm{g}, *}$ \\ a Department of Biological Systems Engineering, Washington State University, Pullman, WA, 99164, USA \\ ${ }^{\mathrm{b}}$ Université de Toulouse, IMT Mines Albi, RAPSODEE CNRS UMR-5302, Campus Jarlard, 81013, Albi cedex, 09, France \\ ${ }^{c}$ Gene and Linda Voiland School of Chemical Engineering and Bioengineering, Pullman, WA, 99164, USA \\ d Department of Physics and Astronomy, Washington State University, Pullman, WA, 99164, USA \\ e Department of Chemistry, Washington State University, Pullman, WA, 99164, USA \\ ${ }^{\mathrm{f}}$ Institute for Integrated Catalysis, Pacific Northwest National Laboratory, Richland, WA, 99352, USA \\ ${ }^{\mathrm{g}}$ Bioproducts Science and Engineering Laboratory, Richland, WA, 99354, USA
}

Keywords:

Density functional theory calculations

$\mathrm{N}$-doped carbons

Raman spectroscopy

\section{A B S T R A C T}

Nitrogen-doped materials are known to possess unique functional properties, making these materials potentially useful for environmental applications, heterogeneous catalysis, and electronics. In this paper we constructed first principles-based models of various polyaromatic structures containing $\mathrm{N}$ functionalities to better understand the effect of these functional groups on char Raman spectra. The presence of $\mathrm{N}$ functional groups induces active vibrations in the regions between 1400 and $1550 \mathrm{~cm}^{-1}$ and $1605-1650 \mathrm{~cm}^{-1}$. We used these insights to inform the deconvolution of $\mathrm{N}$-doped cellulose char produced between 350 and $700{ }^{\circ} \mathrm{C}$ using cellulose/melamine blends $2: 1$. A consistent increase in the intensity of the D and $G$ bands is observed with temperature, which is related to an increase in size of the aromatic cluster. A consistent decrease in the A (the valley region) band is related to the loss of heteroatoms (mainly $\mathrm{N}$ and $\mathrm{O}$ ) as the carbonization temperature increases from 350 to $700{ }^{\circ} \mathrm{C}$. Although the modeling results reported in this manuscript are used to inform the deconvolution of $\mathrm{N}$-doped char Raman spectra, they are also relevant to study other nanocarbon-based materials.

\section{Introduction}

The scientific study of carbonaceous materials derived from lignocellulosic resources has garnered great interest in recent years as their physical, chemical, and electronic properties can be finely tuned through functionalization [1-3]. Such modification is accomplished by changing the nature of the organic precursors and the method of activation, which in turn adjusts the surface chemistry, through incorporation of heteroatoms (e.g. oxygen, sulfur, phosphorus, boron and nitrogen) [4-8]. Property alteration by controlling the surface chemistry of char materials has been shown

* Corresponding author. Department of Biological Systems Engineering, 2710 Crimson Way, Washington State University, Richland, WA, 99354-1671, USA.

** Corresponding author. Voiland School of Chemical Engineering and Bioengineering, Washington State University, 257 Wagner Hall, Pullman, WA, 99164, USA

E-mail addresses: js.mcewen@wsu.edu (J.-S. McEwen), mgarcia-perez@wsu.edu (M. Garcia-Perez). to have advantageous technological implications for electrochemical biosensors [9-12], lithium-ion batteries anodes [13,14], heterogeneous catalysts [15-26], wastewater treatment [27-35], and trace gas adsorption [35-41]. The carbonaceous nanostructure such as graphitic, turbostratic as well as amorphous carbon is significant because it relates to important properties such as electrical conductivity, hardness, strength, fine porosity, and material stability [42-45]. These properties can determine the suitability of a char for a given application, and they can change greatly based on carbonization and activation conditions. Nitrogen doping has been a simple but useful process for graphene and other carbonaceous materials because $\mathrm{N}$-doping easily manipulates the local electronic structure $[46,47]$ and thus improves the device performance in various applications including biosensors [9], fuel cells [48], and electronic devices [49]. In particular, it is known that the manipulated local electronic structures allows for enhanced binding with ions in a solution [23]; this exceptional feature can be utilized for high-capacity energy storage devices. Based on the tremendous 
applications of nitrogen doped carbon materials, it is herein highly important to understand the nature of nitrogen-doped char.

Raman is one of the most commonly used techniques to study the chemical structure of carbonaceous materials [50,51]. It is a promising instrument for probing the configuration of materials because it is sensitive to defects, excess charge (doping), strain and to the atomic arrangement of the edges [52-54]. The interpretation of Raman spectra of nitrogen containing amorphous carbon is extremely challenging due to the lack of reliable information [55]. The two fundamental peaks usually observed in Raman spectra are the G-band, attributed to graphitic carbon, and the D-band, attributed to defects within the graphitic structure. The G-band is located at approximately $1575 \mathrm{~cm}^{-1}$, with $E_{2 g}$ symmetry as the primary Raman active mode for highly ordered regions of graphite crystals $[50,56,57]$. The second distinct mode, the D-band, near $1350 \mathrm{~cm}^{-1}$, with $A_{1 g}$ symmetry, is thought to arise from a fairly disordered structure with defect sites [51,55,58-60]. To further explain the origin of these bands Smith et al. performed gas phase calculations on small polyaromatic structures using DFT-based calculations and attributed the vibrations between $D$ and $G$ bands and also the shoulder of the $\mathrm{D}$ band to 5 -membered, heteroatoms and 7+ membered rings respectively [55]. However, the impact of nitrogen-containing functionalities on char Raman spectra is still unknown.

In this paper both experimental and calculated Raman spectra from small nitrogenated polycyclic aromatic hydrocarbon (PAH) molecules are used in support of the deconvolution of Raman spectra from complex nitrogenated carbonaceous materials, derived from cellulose feedstock processed from 350 to $700{ }^{\circ} \mathrm{C}$. The molecules studied were chosen to represent the effects of nitrogen functionalities. The new insights gained with these studies are used to inform the deconvolution of $\mathrm{N}$-doped chars produced from cellulose.

\section{Materials and methods}

\subsection{N-doped char production}

A series of $\mathrm{N}$-doped chars were produced by carbonization at temperatures ranging from 350 to $700{ }^{\circ} \mathrm{C}$ from cellulose and melamine (cellulose: melamine ratio of $2: 1$ ) in a spoon reactor following the same methods as previously described [55,61,62]. Briefly, the furnace is preheated to a desired temperature while a pre-weighed sample $(4.0 \mathrm{~g})$ is stored in a water-jacketed cooling zone. The cooling zone and furnace are purged with a $\mathrm{N}_{2}$ gas (99\%) stream flowing at approximately $300 \mathrm{~mL} / \mathrm{min}$ for a minimum of $10 \mathrm{~min}$ prior to treatment. At the start of the experiment, the sample is introduced into the furnace and treated for $30 \mathrm{~min}$ and 60 min residence times at the required temperature $\left(350-700{ }^{\circ} \mathrm{C}\right)$ before withdrawal to the cooling zone. A secondary preheated nitrogen sweep gas, flowing at approximately $550 \mathrm{~mL} / \mathrm{min}$, is employed in the reactor zone to avoid char oxidation. Samples were allowed to cool to temperatures below $25{ }^{\circ} \mathrm{C}$ under $\mathrm{N}_{2}$ before exposure to air and later stored in sealed containers.

\subsection{Elemental analysis}

Elemental analysis was performed using a TRUSPEC-CHN ${ }^{\circledR}$ elemental analyzer (LECO, U.S.) [40]. Briefly, $0.15 \mathrm{~g}$ of sample was used to determine total carbon $(\mathrm{C})$, nitrogen $(\mathrm{N})$ and hydrogen $(\mathrm{H})$ contents. Oxygen $(\mathrm{O})$ mass fraction was determined by subtracting the ash, $\mathrm{C}, \mathrm{N}$, and $\mathrm{H}$ contents from the total mass of the sample.

\subsection{Experimental Raman analysis}

Raman spectra were collected for the $\mathrm{N}$ containing standards (Acridine and Carbazole were purchased from sigma Aldrich) using a Horiba LabRAM HR 800. A 250-mW, 532-nm wavelength laser (Ventus LP 532) operated at $90 \%$ of maximum intensity with a $1 \%$ transmittance filter was used for visible light analysis at an objective of 50X. The numerical aperture of the objective is 0.50 . The grating used was $600 \mathrm{gr} / \mathrm{mm}$ so scan ranges were taken and stitched together. We packed the sample in the cell (Linkam CCR1000) and flowed $\mathrm{N}_{2}$ at room temperature for the scans. Duplicate analysis of the initial spot was performed after a $5 \mathrm{~min}$ cooling period to ensure a consistent signal was obtained. Spectra were collected using a Synapse CCD (Charge Coupled Device) detector from a minimum of three separate points on each sample with 3 scans per replicate.

For the char samples, Raman spectra were acquired using a Confocal Raman - AFM WITEC Alpha 300AR microscope equipped with a CCD camera detector $\left(175-4000 \mathrm{~cm}^{-1}\right)$ at room temperature in air. Pellets are prepared with $5 \mathrm{wt} \%$ of char in $\mathrm{KBr}$ (supplied by Fluka), in order to dissipate heating from the laser beam. Spectra were recorded using a $50 \times$ lens $(\mathrm{Na}=0.75)$ and an excitation laser at $532 \mathrm{~nm}$. Each sample was analyzed on at least two zones at the surface (on a square of $5 \times 5 \mu \mathrm{m}^{2}$ ). The cluster option of the Raman software has been applied to each zone to localize similar regions in spectral data sets. Based on the spectral data, the number of clusters has been kept to 2 . Maximum laser power $42 \mathrm{MW}$, however, $20 \%$ of the maximum value was used to acquire spectra from all samples for consistency across the range of materials analyzed. Spectra were then compared in each zone and we used the spectrum with highest intensity for curve-fitting, in order to reduce the impact of the noise using the Origin pro software. Based on the information gathered from the computational calculations, the real $\mathrm{N}$-doped char was deconvoluted into 9-11 Gaussian peaks. We highlight that in all the measurements we have consistently used the same laser excitation frequency $(532 \mathrm{~nm})$. Thus, we can exclude spurious shifts due to changes in the laser frequency. Previous studies showed that the $\mathrm{D}$ band has a dispersive behavior whereby the $\mathrm{D}$ band frequency changes with the energy of the incident laser [63].

\subsection{Computational details}

Simulations were conducted on a range of defective structures with $\mathrm{N}$ functionalities based on an initial coronene system. Coronene was selected as the basis for defect studies as it represents the smallest PAH in which single- and double-point defects can be easily introduced. All calculations were done based on the same procedure established my Smith et al. [55]. Briefly, all compounds have been evaluated using most abundant isotopes in the Gaussian 09 rev. B.01 software package. Geometry optimizations and frequency analyses were completed using the Becke three-parameter Lee-Yang-Parr (B3LYP) hybrid functional and all systems were evaluated at the 6-31G* basis set. Input parameters for each compound studied were constructed using the WebMO platform [64]. After optimization of the geometry and force constants at the desired theory level, frequency calculations were performed at the static limit. Raman spectra and vibrational modes are visualized using the WebMO tool [64]. Previous research using PAHs have demonstrated effective prediction of Raman peak positions with DFT after appropriate scaling [65]. Hence, all data were corrected by a scaling factor of 0.9726 which accounts for the approximations been introduced when using the 6-31G* basis set. Finally, all spectra were normalized based on the peak of maximum intensity between 600 and $2000 \mathrm{~cm}^{-1}$ for comparison. 


\section{Results and discussions}

\subsection{Benchmarking DFT-based Raman spectra}

Fig. 1 presents the benchmarked results of the Raman spectra of real model compounds such as anthracene, acridine, aminoanthracene as well as benzo(h)quinoline and carbazole. These structures represent the class of smaller systems which might be found in nitrogenated carbonaceous materials like char. In carbazole the lone pair is in pure $p$ orbital, and participates to the electronic cloud. In acridine the lone pair is in a $s p^{2}$ orbital. In both cases system are conjugated ( 6 electrons per ring). The experimental and theoretical peak positions of acridine and carbazole are shown in Table 1 . The matches look reasonably acceptable. Most/all major to moderate modes are captured within a reasonable approximation of their experimental positions.

Fig. 2 shows the Raman spectra of all the model structures. The results are summarized in Table 2. Anthracene, acridine, and amino-anthracene present the same type of peak situated at about $1400 \mathrm{~cm}^{-1}$. This peak is associated to breathing type vibrations in these molecules. However, for large PAHs structures (e.g. coronene), the center breathing mode is located at approximately $1350 \mathrm{~cm}^{-1}$. The peak at around $1500 \mathrm{~cm}^{-1}$ is associated to the center breathing coupled with a Kekulé mode in peripheral rings of the structures. For the benzo(h)quinoline, the change in structural arrangement leads to the splitting of the peak located at about $1400 \mathrm{~cm}^{-1}$ into multiple peaks, but with the Kekule mode in all the rings. Interestingly, Carbazole (5-membered ring structure) shows two peaks at 1287 and $1332 \mathrm{~cm}^{-1}$, which corresponds to the stretching of the $\mathrm{C}-\mathrm{N}$ bond and $\mathrm{C}-\mathrm{C}$ bond in the 5-membered ring
Table 1

Comparison of experimental and DFT frequencies of acridine and carbazole as represented in Fig. 1.

\begin{tabular}{llc}
\hline Peak Position & $\begin{array}{l}\text { Experimental } \\
v\left(\mathrm{~cm}^{-1}\right)\end{array}$ & $\begin{array}{l}\text { DFT } \\
\mathrm{v}\left(\mathrm{cm}^{-1}\right)\end{array}$ \\
\hline Acridine & & \\
\hline A & 1017 & 1014 \\
B & 1400 & 1404 \\
C & 1483 & 1498 \\
D & 1555 & 1557 \\
\hline Carbazole & & \\
\hline A & 1012 & 1024 \\
B & 1286 & 1287 \\
C & 1333 & 1332 \\
D & 1446 & 1460 \\
E & 1472 & 1499 \\
F & 1568 & 1592 \\
G & 1620 & 1640 \\
\hline
\end{tabular}

respectively; these movements correspond to a frustrated breathing mode of the 5-membered ring. The peaks at 1592 and $1640 \mathrm{~cm}^{-1}$ are the intense breathing of the 5-membered ring and the asymmetric stretching of the $\mathrm{C}-\mathrm{C}$ bonds respectively. All the structures show a weak peak at about $1000 \mathrm{~cm}^{-1}$ that is attributed to the breathing mode of individual benzene structures. Also, we were able to assess that most nitrogen-containing structures show some vibrations above $1600 \mathrm{~cm}^{-1}$. These peaks located within this region are normally referred to as a $\mathrm{D}^{\prime}$ peak which arise as a result of defects, such as doping [56,66,67]. Ferrari et al. [60] explained in his studies that modes above $1600 \mathrm{~cm}^{-1}$ are mostly due to the

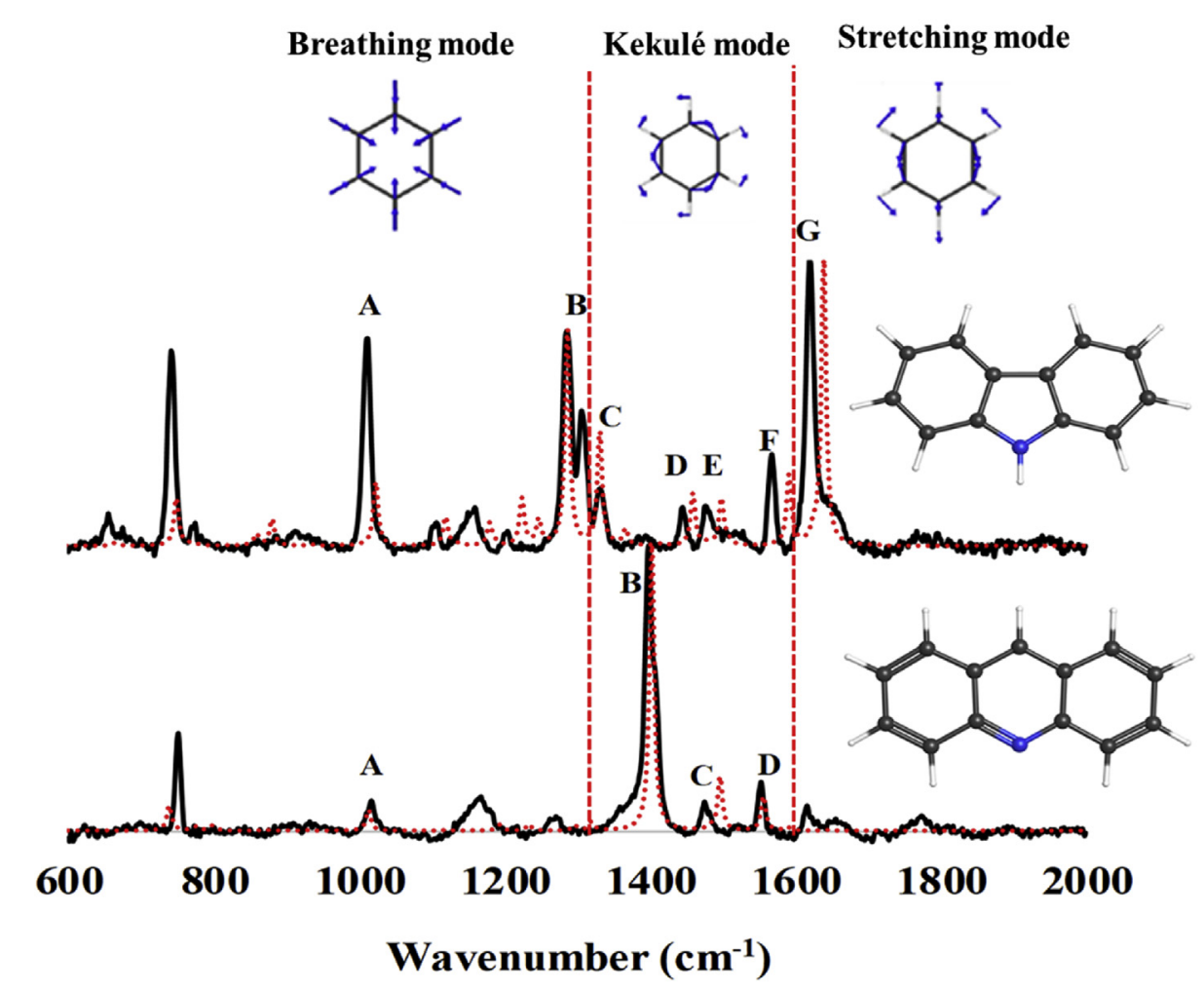

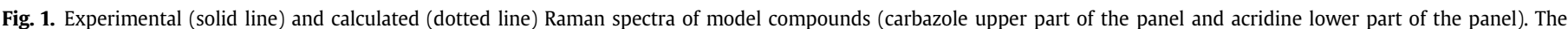

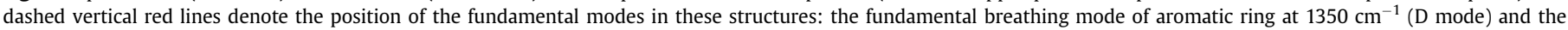

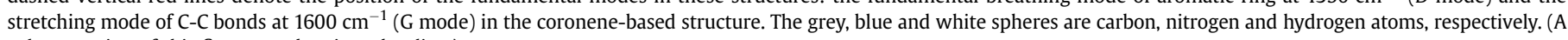
colour version of this figure can be viewed online.) 


\section{Breathing mode Kekulé mode Stretching mode}

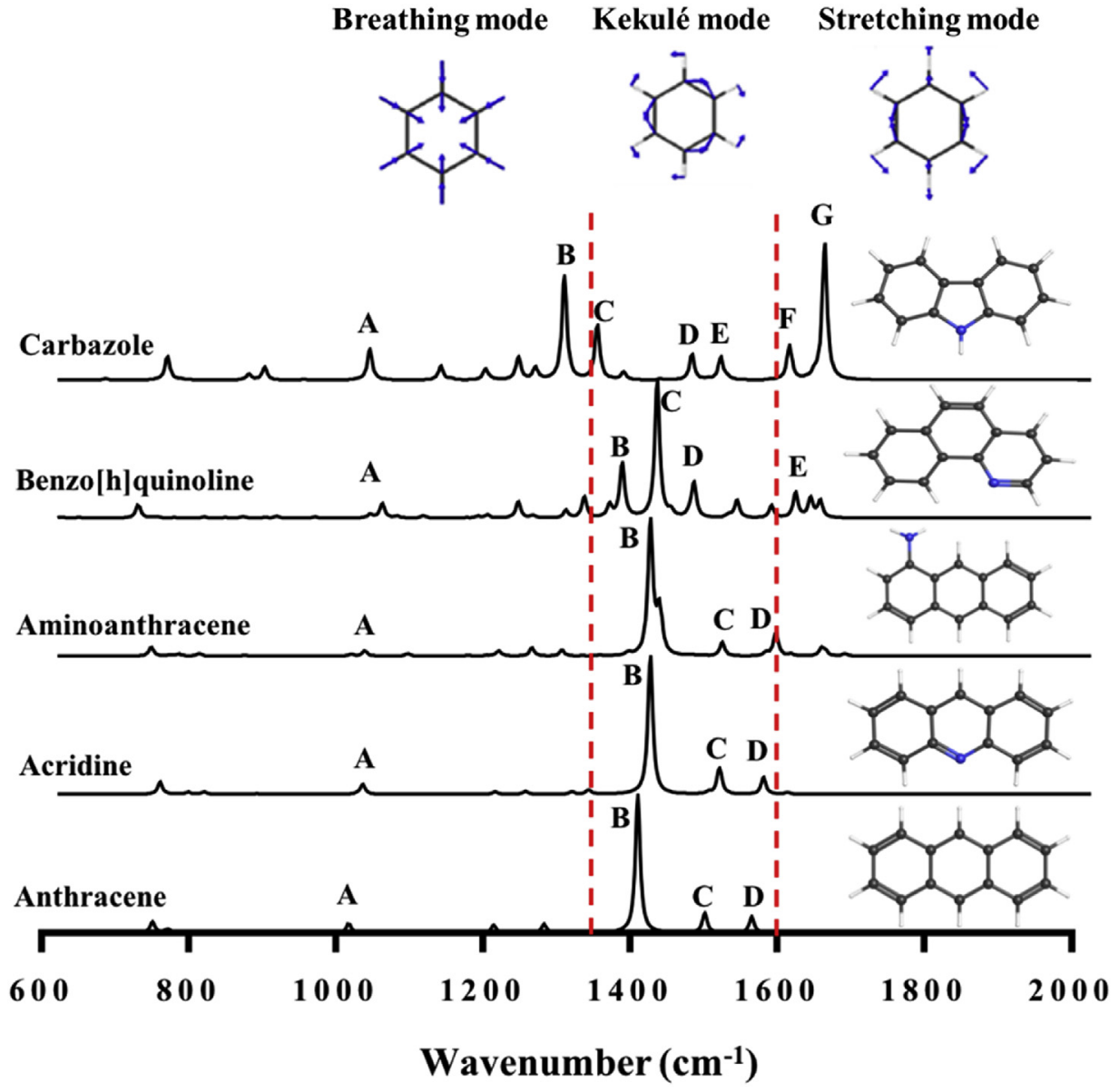

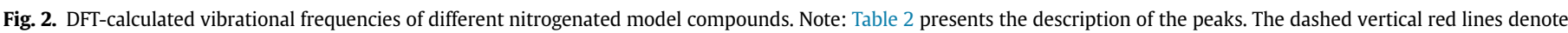

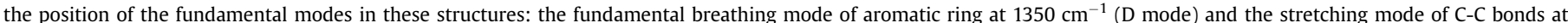

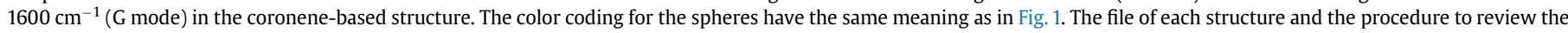

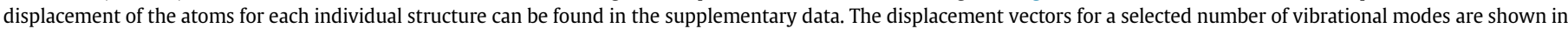
Figs. S1, S2, S3, S4 and Table S1. (A colour version of this figure can be viewed online.)

presence of doped atoms, which leads to a $s p^{3}$ character in some carbon atoms. They also observed the $G$ band position of a tetrahedral amorphous carbon to decrease from $1690 \mathrm{~cm}^{-1}$, which had a $88 \% s p^{3}$ content. Further, the $s p^{3}$ content decreased to zero at $1585 \mathrm{~cm}^{-1}$.

In order to have a broad understanding on the effect of nitrogen inclusions on moderately large systems, coronene was used as reference molecule. Fig. 3 shows the theoretically calculated gas phase Raman spectra using coronene as a base structure with two of them containing graphitic nitrogen. The results are summarized in Table 3. It is important to note that the symmetry of coronene is $D_{6 h}$, however after the introduction of nitrogen within the structure, the symmetry breaks down to $C_{1}$. The spectra of coronene highlights two fundamental modes: the center breathing mode of the ring located at about $1349 \mathrm{~cm}^{-1}$ and the asymmetric stretching of the $C-C$ bonds located at 1610 and $1621 \mathrm{~cm}^{-1}$. These $\mathrm{G}$ band positions are similar to what has been previously reported for nanocrystalline graphite [68]. The peak at $1349 \mathrm{~cm}^{-1}$ (also known as the D band) is more dominant than the other peaks. This is because coronene is a finite polycrystalline sheet with edge sites sufficiently unrestricted to vibrate. The introduction of nitrogen groups drastically affects the Raman spectra by activating new peaks that were initially not observed in the spectra of coronene. Breaking down the symmetry leads to the activation of new modes [55].

\subsection{Simulation of the effect of graphitic nitrogen on Raman spectra}

Fig. 4 shows the computational results of the modification of coronene around a single point defect (SPD-N) and a double point defect (DPD-N). The introduction of nitrogen in the structure reduced the symmetry of the structure from $D_{6 h}$ to $C_{1}$ symmetry. Vibrations seen at 1200 and $1300 \mathrm{~cm}^{-1}$ in the SPD-N-I structure are related to the breathing mode of the whole structure, as well as assorted vibrations related to the breathing and Kekule modes of different moieties. Vibrations between 1350 and $1400 \mathrm{~cm}^{-1}$ are related to the breathing mode of the center ring and Kekule mode in the peripheral rings. The Kekulé mode mixed with either breathing of different PAHs moieties or stretching of $s p^{2}$ carbons dominates the 1400 and the $1600 \mathrm{~cm}^{-1}$ region. The asymmetric stretching of $s p^{2}$ carbons are more active for vibrations within the $1600 \mathrm{~cm}^{-1}$ and the $1650 \mathrm{~cm}^{-1}$ regions. We observe that nitrogen introduction leads to activation of peaks at about $1650 \mathrm{~cm}^{-1}$. This area correlates to the $\mathrm{D}^{\prime}$ region, which in the literature is related to heteroatom defects [69-71].

The presence of nitrogen in the SPD-N-I structure activated three different peaks in the region between 1600 and $1670 \mathrm{~cm}^{-1}$. The first peak represents asymmetric stretching of all $s p^{2}$ carbons, but it is more intense in the anthracene-like structures. The next peak is also a stretching mode that is present in two rings isolated away from the nitrogen (i.e. Naphthalene-like structure). The last 
Table 2

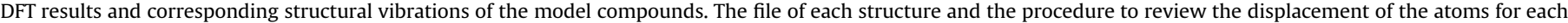
individual structure can be found in the supplementary data. The displacement vectors for the vibrational modes are shown in Figs. S1, S2, S3, S4 and Table S1.

\begin{tabular}{|c|c|c|c|}
\hline Peaks & $\mathrm{V}\left(\mathrm{cm}^{-1}\right)$ & Normalized Intensity & Vibrational Modes \\
\hline \multicolumn{4}{|c|}{ Acridine } \\
\hline A & 1014 & 0.07 & Breathing of the 2 external benzenes structures \\
\hline B & 1404 & 1.00 & Center breathing in the rings \\
\hline $\mathbf{C}$ & 1498 & 0.19 & Center ring breathing and Kekulé in peripheral rings \\
\hline D & 1557 & 0.12 & Stretching of the $\mathrm{C}-\mathrm{C}$ bonds \\
\hline \multicolumn{4}{|c|}{ Aminoanthracene } \\
\hline A & 1017 & 0.04 & Frustrated breathing mode of the external ring with the amine group \\
\hline B & 1404 & 1.00 & Kekulé in ring with amine group \\
\hline $\mathbf{C}$ & 1501 & 0.10 & Center ring breathing and Kekulé in peripheral rings \\
\hline D & 1574 & 0.17 & Stretching of the C-C bonds \\
\hline \multicolumn{4}{|c|}{ Benzo(h)quinoline } \\
\hline A & 1040 & 0.11 & Breathing of the 2 external benzenes structures \\
\hline B & 1366 & 0.40 & Kekulé, more intense in the ring not attached to pyridine \\
\hline $\mathbf{C}$ & 1413 & 1.00 & Frustrated breathing of the pyridine ring \\
\hline D & 1463 & 0.26 & Kekulé in whole structure \\
\hline $\mathbf{E}$ & 1601 & 0.19 & Asymmetric stretching of the $\mathrm{C}-\mathrm{C}$ bonds, but more intense in the pyridine ring \\
\hline \multicolumn{4}{|c|}{ Carbazole } \\
\hline A & 1024 & 0.22 & Breathing of the 2 benzenes structures attached to the 5-membered ring \\
\hline B & 1287 & 0.76 & Stretching of $\mathrm{C}-\mathrm{N}$ bond in the 5 -membered ring \\
\hline $\mathbf{C}$ & 1332 & 0.40 & Stretching of $\mathrm{C}-\mathrm{C}$ bond in the 5-membered ring and hydrogen wagging \\
\hline D & 1460 & 0.18 & Kekulé in the external rings coupled with semi-breathing of 5-membered ring \\
\hline $\mathbf{E}$ & 1499 & 0.17 & Kekulé in the external rings coupled with semi-breathing of 5-membered ring \\
\hline $\mathbf{F}$ & 1592 & 0.25 & Intense breathing of the of the 5-membered ring combined with Kekule in the external rings \\
\hline G & 1640 & 1.00 & Asymmetric stretching of the $\mathrm{C}-\mathrm{C}$ bonds \\
\hline
\end{tabular}

peak is also due to an asymmetric stretching mode but is more intense in the rings containing nitrogen.

The presence of nitrogen in the basal plane (SPD-N-II) produces similar peaks as to the ones shown in SPD-N-I. Nevertheless, a different behavior is observed when a pyrrolic group (5-membered ring with nitrogen) is introduced in the structure (see SPD-N-III in Fig. 4). The first peak from left to right shows the breathing of the center ring and the Kekule mode in the peripheral rings; this peak has been slightly red shifted $\left(1342 \mathrm{~cm}^{-1}\right)$ relative to the peak found in coronene $\left(1349 \mathrm{~cm}^{-1}\right)$. The second peak, which is the most intense peak $\left(1378 \mathrm{~cm}^{-1}\right)$, represents a frustrated breathing mode of the center of the ring and Kekule mode in the outer rings. An intense Kekule mode coupled with $s p^{2}$ stretching of all rings is located at approximately $1680 \mathrm{~cm}^{-1}$. Finally, based on our previous work [72], we anticipate that the SPD-N-II structure will be less favorable thermodynamically. As such, we anticipate that the Raman spectra with the incorporation of $\mathrm{N}$ at the edge of the coronene structure will correlate better with the Raman spectra of biochar.

Interestingly, the presence of more than one nitrogen group in the structure depicts very important peaks in between the 1400 $\mathrm{cm}^{-1}$ to $1550 \mathrm{~cm}^{-1}$ region. These peaks represent the asymmetric stretching of different ring systems. The peak near $1250 \mathrm{~cm}^{-1}$ in the DPD-N-I structure shows the breathing mode of the whole structure. This might be attributed to the fact that the electrons of the two nitrogen's are distributed symmetrically within the structure. Interestingly, the DPD-N-II structure has the same peaks in the $1000 \mathrm{~cm}^{-1}$ to $1300 \mathrm{~cm}^{-1}$ frequency range. However, the corresponding intensities for the DPD-N-II structure are very low as compared to those of the DPD-N-I structure. Putting it simply, while replacing nitrogen with carbon maintains the planar structure, it breaks the symmetry. This leads to the activation of new vibrational modes and splitting of existing modes. New modes at about $1650-1675 \mathrm{~cm}^{-1}$ appear due to the presence of nitrogen. Other modes between $1400 \mathrm{~cm}^{-1}$ and $1550 \mathrm{~cm}^{-1}$ are associated with assorted mixtures of stretching and Kekulé modes. Increasing the number of nitrogen atoms increases the intensity of vibrations in the region between 1400 and $1550 \mathrm{~cm}^{-1}$. Interestingly, the pyrrolic structure at the edge increases the intensity in the region between 1350 and $1400 \mathrm{~cm}^{-1}$ but suppresses the intensity of $\mathrm{sp}^{2}$ stretching mode.

\subsection{Effect of nitrogen functional groups and defects on the Raman spectra}

To get a detailed understanding with regard to the effect of nitrogen functionalities on the distribution of the vibrational modes, more defective structures were created with the functionalities inserted in these defective regions (See Fig. 5). Our previous work has shown that the presence of such defects are essential to ensure the thermodynamic favorability of such structures when $\mathrm{N}$ is not at the edge of the coronene-based compound [72]. The presence of 2 pyridine groups in the coronene structure (as is the case in the DPD-N-III structure) has an impact on the spectra, where the peak near $1200 \mathrm{~cm}^{-1}$ is due to a frustrated breathing mode of the open center ring; the mode is hindered by the presence of these nitrogen groups. The region between $1300 \mathrm{~cm}^{-1}$ and $1400 \mathrm{~cm}^{-1}$ represents the assorted vibrations of different moieties within the structure, principally the breathing mode of rings with defects and a Kekule vibrational mode of the intact rings. On the other hand, the principal asymmetric stretching is red shifted to $1539 \mathrm{~cm}^{-1}$ relative to coronene. The rest of the peak between $1550 \mathrm{~cm}^{-1}$ and $1620 \mathrm{~cm}^{-1}$ is related to a combination of the fundamental stretching of $s p^{2}$ carbons and a Kekule vibrational mode in the rings that have nitrogen incorporated into them. The peaks observed in the DPD-N-II structure are similar to those already seen in the DPD-N-III structure.

The formation of a 5-membered ring in the observed DPD-N-I structure gives a much more complex spectra but with more of the intensified peaks located in the $\mathrm{G}$ mode (stretching) region. The 


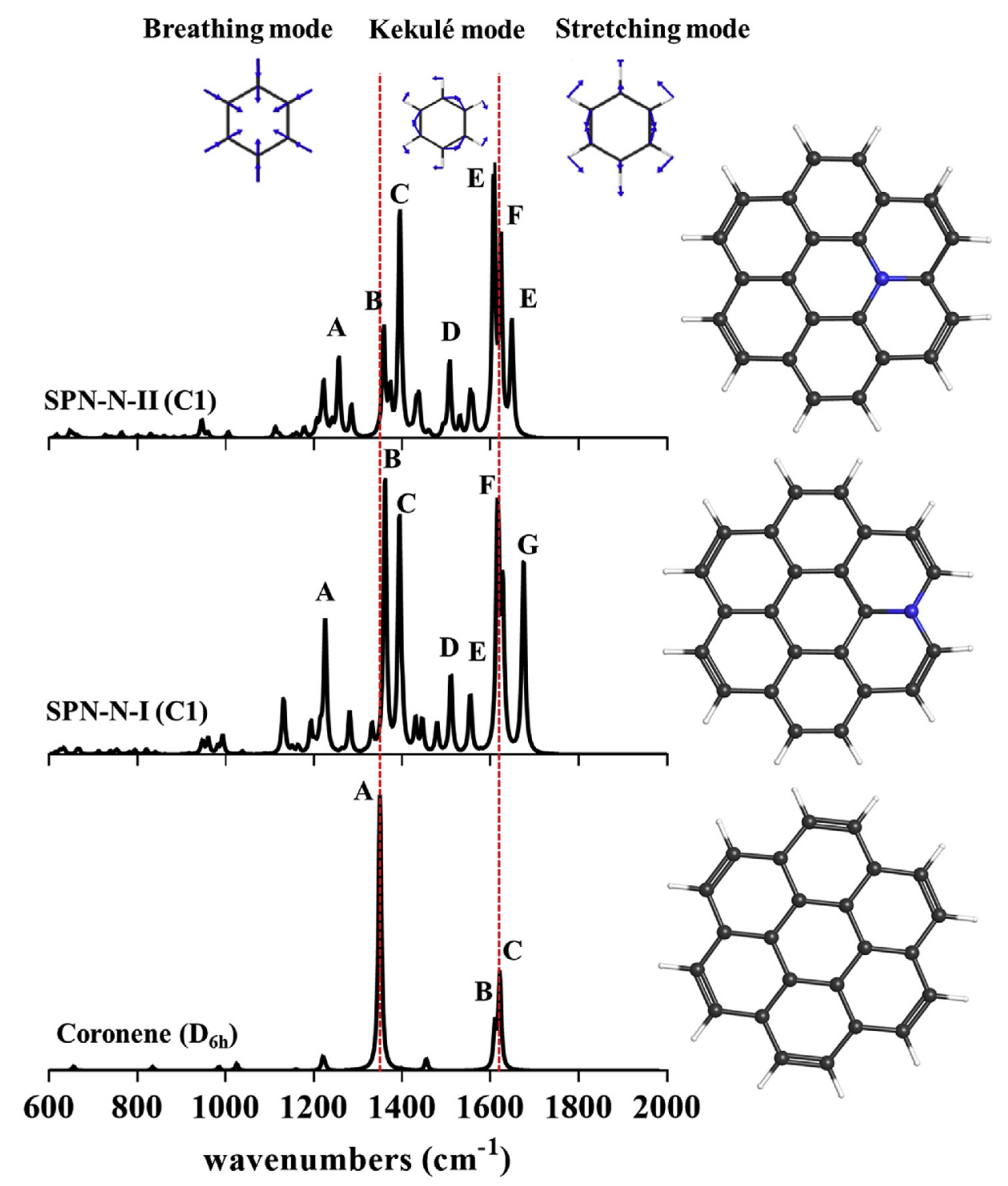

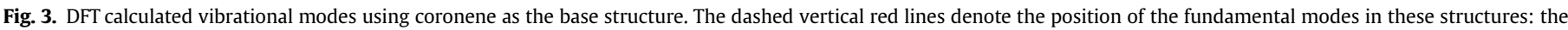

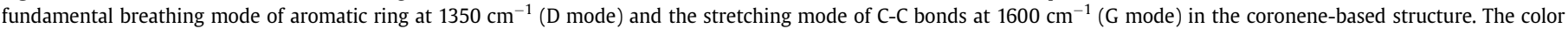

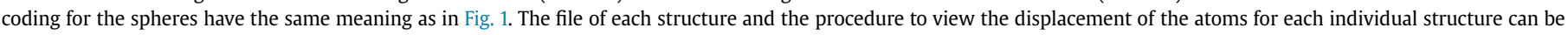

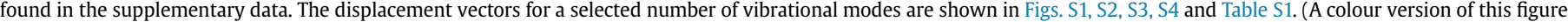
can be viewed online.)

most intense peak is located at $1583 \mathrm{~cm}^{-1}$, corresponding to the stretching of $s p^{2}$ carbons and semi breathing of the larger ring with nitrogen. The peaks of higher frequency above $1600 \mathrm{~cm}^{-1}$ relates to the stretching of the $\mathrm{C}-\mathrm{C}$ bond in the six-membered ring with nitrogen. Finally, forming a pyridinic structure at the edge of the coronene molecule does not activate any new vibrational mode. In summary, creating vacancies within the coronene structure influences the Raman spectra by activating new vibrational modes. However, $\mathrm{N}$ groups within the defective regions also contribute to the splitting of the $G$ band. Pyridine groups at the edge of a nondefective coronene structure has practically no effect on the vibration modes.

\subsection{Effect of nitrogen and oxygen functional groups in both defects and edge sites}

Fig. 6 shows the effect of various point defects of nitrogen and oxygenated functionalities on the calculated Raman spectra of a coronene-based molecule. Introduction of heteroatoms reduces the symmetry of the molecules to a $\mathrm{C} 1$ point group. Note that the Raman spectra of the Pyridine N Oxide (C1) structure and the Pyridone (C1) structure (groups at the edge of coronene) is practically similar to the parent molecule (coronene). However, the Pyridone (C1) structure shows a splitting of the peak located at $1349 \mathrm{~cm}^{-1}$ and a higher intensity of the stretching of the $C-C$ bonds at around $1610 \mathrm{~cm}^{-1}$ as compared to coronene. Besides that, the peak located at $1726 \mathrm{~cm}^{-1}$ represents the stretching of the carbonyl group, consistent with the findings of Smith et al. [55]. Additionally, a pyridone (DPD-O-N-I) functional group was also introduced in a vacancy area to evaluate its effect on the Raman spectra. It is observed that while the $G$ band is split into several peaks which appear as a broad band, the sharp peak at $1385 \mathrm{~cm}^{-1}$ is associated to a Kekule vibration of the intact rings. Finally, our previous work [73] has shown that the Pyridone (C1) structure is more favorable thermodynamically than the Pyridine N Oxide (C1) structure over a wide range of temperatures and pressures, which is consistent 
Table 3

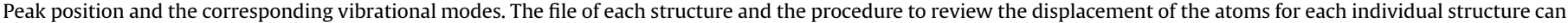
be found in the supplementary data (Figs. S1, S2, S3, S4 and Table S1).

\begin{tabular}{|c|c|c|c|}
\hline Peaks & $v\left(\mathrm{~cm}^{-1}\right)$ & Intensity & Vibrational Mode \\
\hline \multicolumn{4}{|c|}{ Coronene $\left(D_{6 h}\right)$} \\
\hline A & 1349 & 1.00 & Center breathing periphery Kekulé mode \\
\hline B & 1610 & 0.19 & Center breathing per asymmetric stretch \\
\hline C & 1621 & 0.36 & Asymmetric stretch \\
\hline \multicolumn{4}{|c|}{ SPD-N-I $\left(C_{1}\right)$} \\
\hline A & 1291 & 0.29 & Frustrated center breathing periphery Kekulé mode \\
\hline B & 1359 & 0.4 & Center breathing Kekulé per rings \\
\hline $\mathbf{C}$ & 1395 & 0.83 & Frustrated center breathing Kekulé PAHs moiety except near N \\
\hline D & 1508 & 0.28 & Kekulé mode \\
\hline $\mathbf{E}$ & 1608 & 1 & Asymmetric stretch \\
\hline $\mathbf{F}$ & 1623 & 0.74 & Frustrated center breathing asymmetric stretch more intense in rings without $\mathrm{N}$ \\
\hline G & 1649 & 0.43 & Kekulé asymmetric stretch more intense in rings with $\mathrm{N}$ \\
\hline \multicolumn{4}{|c|}{ SPD-N-II(C $\left.C_{1}\right)$} \\
\hline A & 1227 & 0.5 & Frustrated breathing Kekulé mode \\
\hline B & 1360 & 1.0 & Center breathing Kekulé mode \\
\hline C & 1395 & 0.9 & Frustrated center breathing per Kekulé mode \\
\hline D & 1511 & 0.3 & Kekulé mode \\
\hline $\mathbf{E}$ & 1555 & 0.21 & Kekulé mode \\
\hline $\mathbf{F}$ & 1615 & 0.8 & Asymmetric stretch mode \\
\hline G & 1675 & 0.7 & Asymmetric stretch PAHs mode moiety near $\mathrm{N}$ (more intense) \\
\hline
\end{tabular}

\section{Breathing mode Kekulé mode Stretching mode}

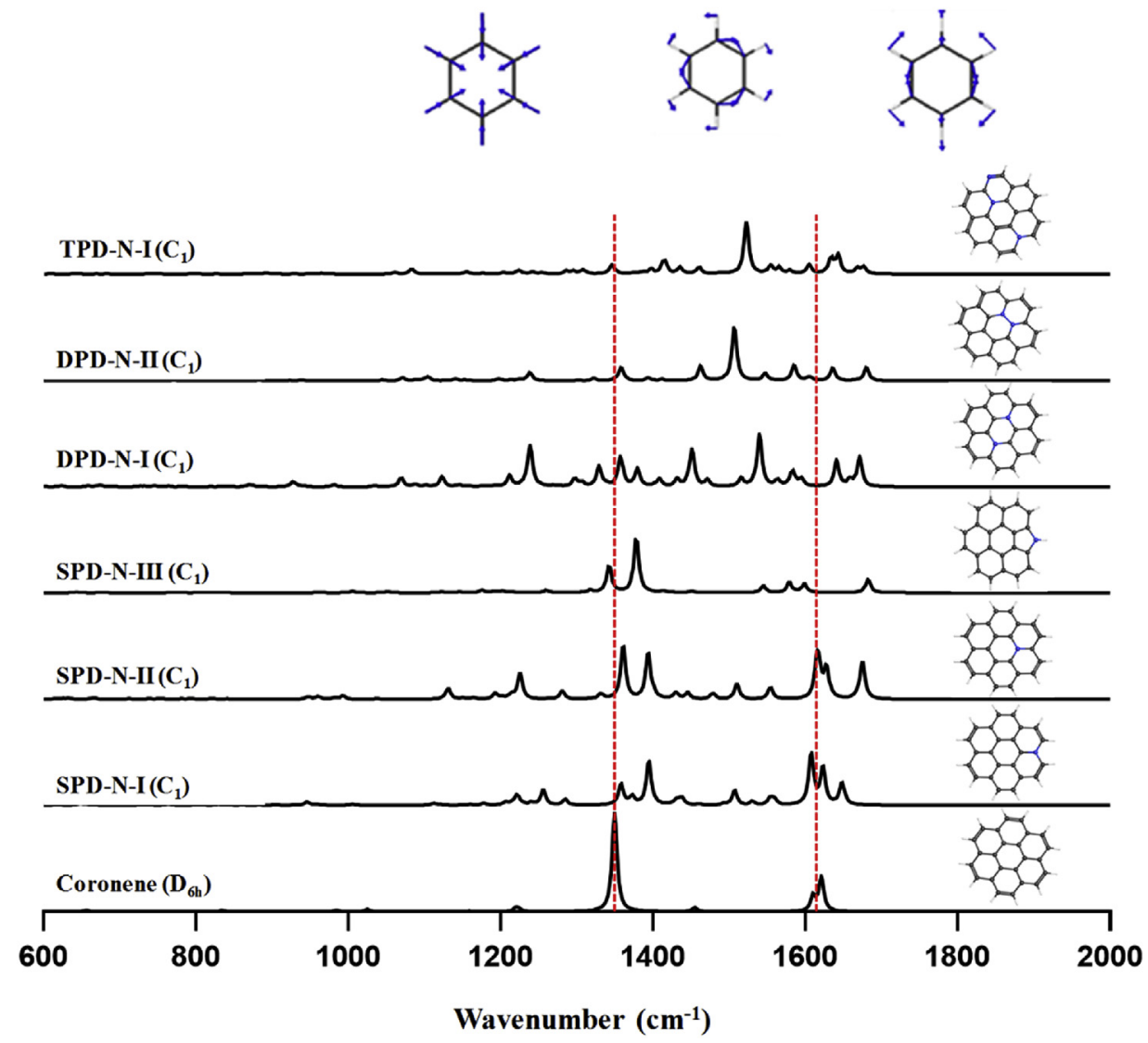

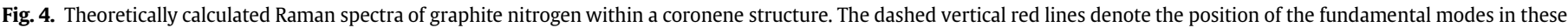

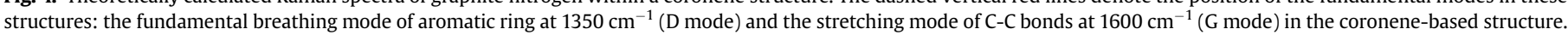

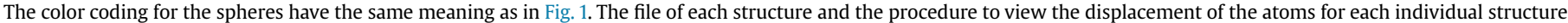
can be found in the supplementary data (Figs. S1, S2, S3, S4 and Table S1). 

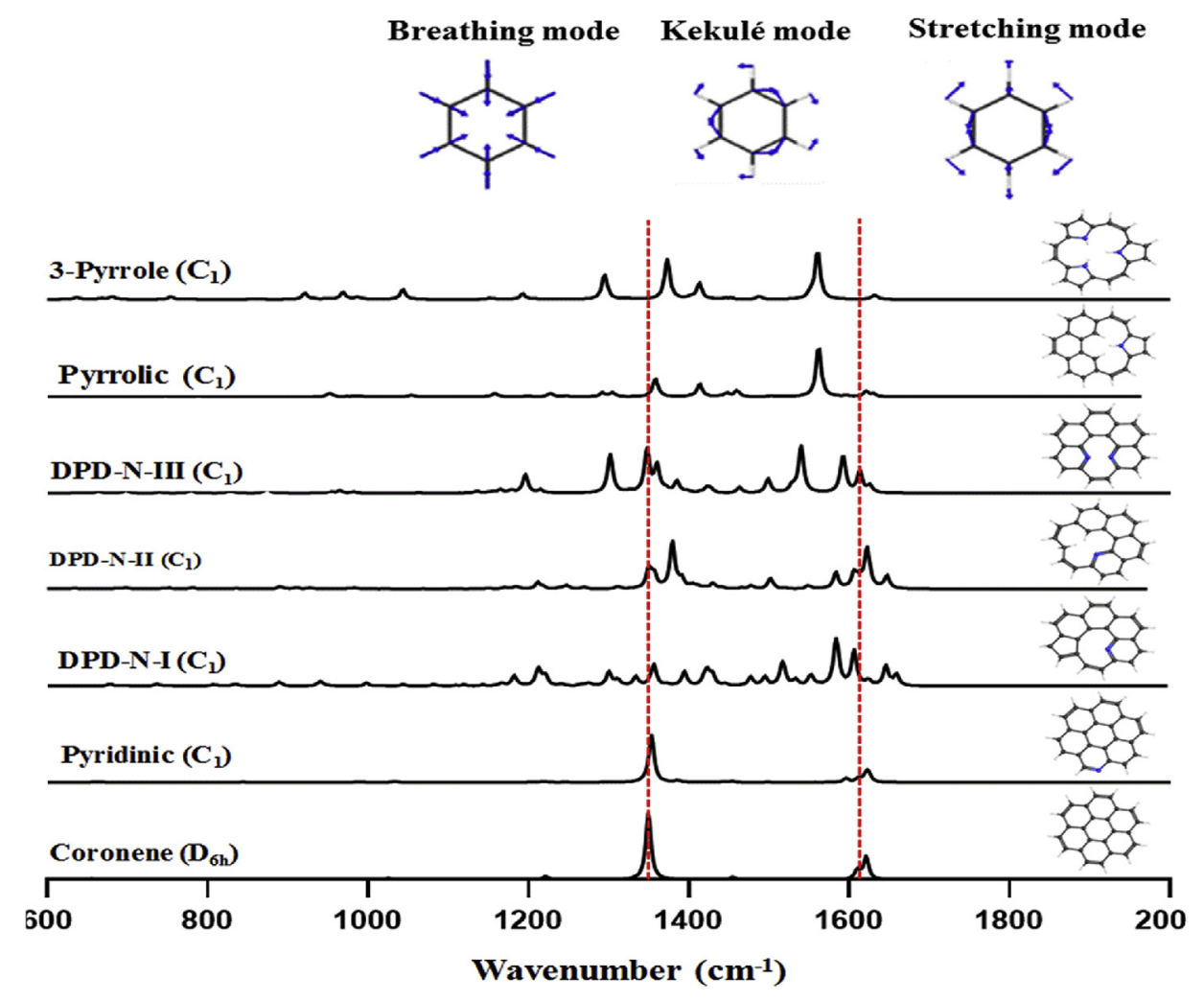

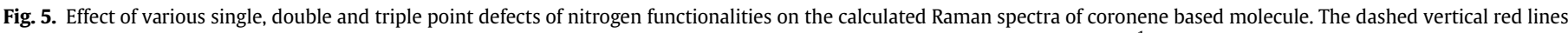

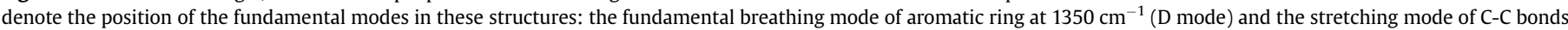

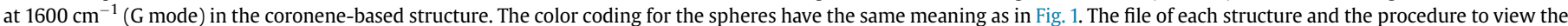

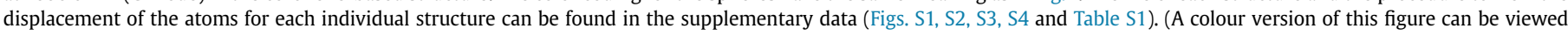
online.)

with our results as related to the coronene based structures as discussed in Section 3.2, where the incorporation of $\mathrm{N}$ into the on the edge of a coronene edge based structure is more favorable thermodynamically.

When $\mathrm{N}$ and $\mathrm{O}$ are not at the edge of the coronene based structure, such as in the DPD-O-N-II structure, the spectra is much more complex. In the case of the DPD-O-N-II spectrum, most of the intense peaks are situated in the region between the $\mathrm{D}$ and $\mathrm{G}$ band, which normally represent the primary region of uncertainty in char. These peaks in the region between 1400 and $1550 \mathrm{~cm}^{-1}$ and are linked to the breathing mode of the rings carrying the heteroatoms and Kekulé mode in the rest of the rings. Notice that from the spectra of the DPD-O-N-III structure and the DPD-O-N-II structure, the principal asymmetric stretching has been red shifted to $1560 \mathrm{~cm}^{-1}$ relative to the parent structure. Finally, as shown in our previous work, we do note that these structures could become thermodynamically favorable if the pressure is sufficiently high [73]. In a partial conclusion, functional groups (pyridine and Noxide) at the edge of a coronene structure do not change the Raman spectra significantly. It can be observed that the Pyridine N Oxide (C1) structure essentially did not change the spectra but the Pyridone (C1) structure did split the $A_{1 g}$ (breathing mode) into two peaks, which might be due to unequal distribution of electron on the system. The electronegativity has an influence in the asymmetrical distribution of the electrons. This limits the vibration of some rings close to the double bonded oxygen, causing peak splitting.

\subsection{Effect of nitrogen functional groups and non-hexagonal ring systems}

Finally, we have investigated the Raman spectra of a 5-8-5 structure with a nitrogen defect. The optimized 5-8-5 defect does have a local curvature (See Fig. 7). The curvature would be determined by the balance of the energy gained due to the 5-8-5 defect relaxation and the energy loss due to the strain induced on the nearby graphitic carbons. Overall, the Raman spectra for the 5-8-5 defect structure and the S-Graphitic-N(C1) structure have a lot of new features. For the 5-8-5 structure, the region between 1000 and $1200 \mathrm{~cm}^{-1}$ represent the breathing of the 8 -membered ring, while between 1450 and $1550 \mathrm{~cm}^{-1}$, the vibration is mostly due to the vibration of the 5 -membered ring systems. It is clearly seen that there are some peaks above $1600 \mathrm{~cm}^{-1}$. Specifically, the 5-8-5 structure has Raman peaks at $1708 \mathrm{~cm}^{-1}$. Upon examination of the atoms participating in these normal modes, we find that these vibrations derive from the displacements of the carbon atoms in the 8-membered ring. However, the S-Pyridinic-N(C1) practically maintains the spectra of the parent "coronene" structure. In summary, it is noted that graphitic nitrogen (nitrogen within the carbon network) causes a blue shift above $1600 \mathrm{~cm}^{-1}$. However, nitrogen at the edge, such as for pyridine, did not show any major significant changes to the spectra. We also remark that these structures are less favorable thermodynamically as compared to the SPD-N-I structure and would also anticipate that they would form at sufficiently higher pressures [73]. 


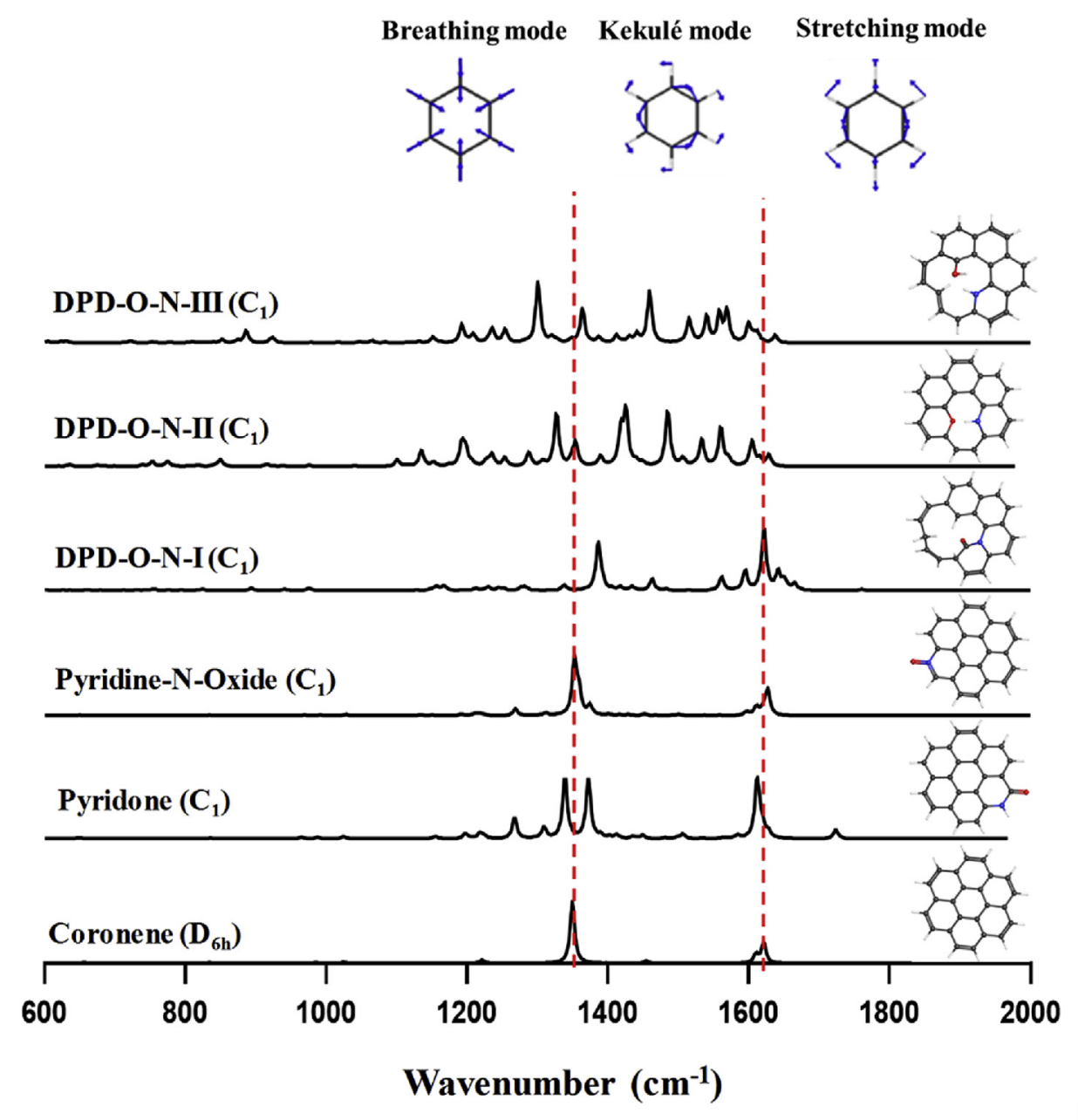

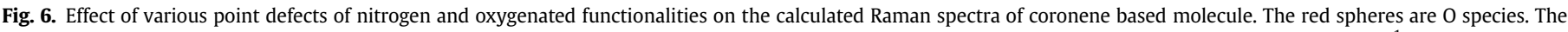

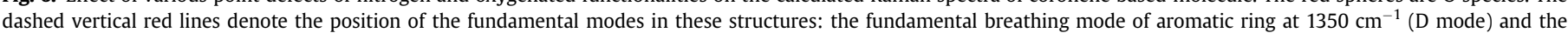

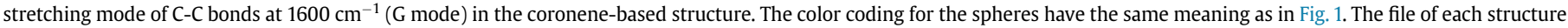

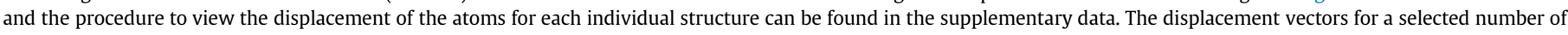
vibrational modes are shown in Figs. S1, S2, S3, S4 and Table S1. (A colour version of this figure can be viewed online.)

\subsection{Effect of cluster size on the vibration spectra}

Previous NMR studies in the literature have estimated that small PAHs like coronene are representative of the average molecular structure of char [74-76]. Based on this, it is important to computationally evaluate various cluster sizes to better understand the spectral features. This section evaluates the effect of cluster size on the distribution of Raman spectra (see Fig. 8). The typical vibrations found are summarized in Table 4. The $\mathbf{C}_{\mathbf{9 6}}$ (C1) structure has essentially only one main peak around $1350 \mathrm{~cm}^{-1}$, corresponding to the breathing mode of the PAH structure. On the other hand, the intensities of the $A_{1 G}$ breathing/Kekule modes and the $E_{2 G}$ vibrational modes of the $C_{96}(C 1)$ structure (around $1600 \mathrm{~cm}^{-1}$ ) are significantly smaller as compared to vibrational modes around $1350 \mathrm{~cm}^{-1}$. This is contrast to the smaller PAH structures such as coronene, where the ratio of the $\sim 1350 \mathrm{~cm}^{-1} \mathrm{~A}_{1 \mathrm{G}}$ breathing mode to the $A_{1 G}$ breathing/Kekule and the $E_{2 G}$ vibrational modes at $\sim 1600 \mathrm{~cm}^{-1}$ are within a factor of three. As such, the presence of non-negligible intensities around $1600 \mathrm{~cm}^{-1}$ in N-doped biochar likely correlates with the presence of smaller PAH structures such coronene, while larger PAHs $\left(\mathrm{C}_{96}\right)$ can also contribute to the Raman features around $\sim 1350 \mathrm{~cm}^{-1}$. Fig. 9 shows the peak position of both the $D$ and $G$ band with respect to the cluster size. An increase in cluster size leads to significant shift in the position of the D band toward lower wavenumbers. Smaller clusters like pyrene and naphthalene have their D peak located in between 1400 and $1480 \mathrm{~cm}^{-1}$. These results indicate that smaller clusters can also contribute significantly to the high intensity between the D and G band.

\subsection{Deconvolution of the Raman spectra of cellulose derived $N$ - doped char}

After carefully analyzing the theoretical Raman spectra, an understanding of the vibrational features of different nitrogenated and non-nitrogenated structures is achieved. These structural features are summarized in Table 5. These were then used as a guideline to deconvolute real nitrogen doped char spectra.

\subsubsection{Experimental Raman spectra}

Fig. 10 below displays the experimental Raman spectra of chars both with and without $\mathrm{N}$-doping produced at temperatures from 350 to $700{ }^{\circ} \mathrm{C}$. It is important to note that in this manuscript we used the spectrum with the highest intensity for curve-fitting. It means that the spectra fitted likely describe the composition of one of the phases present in the char. The elemental composition of the 


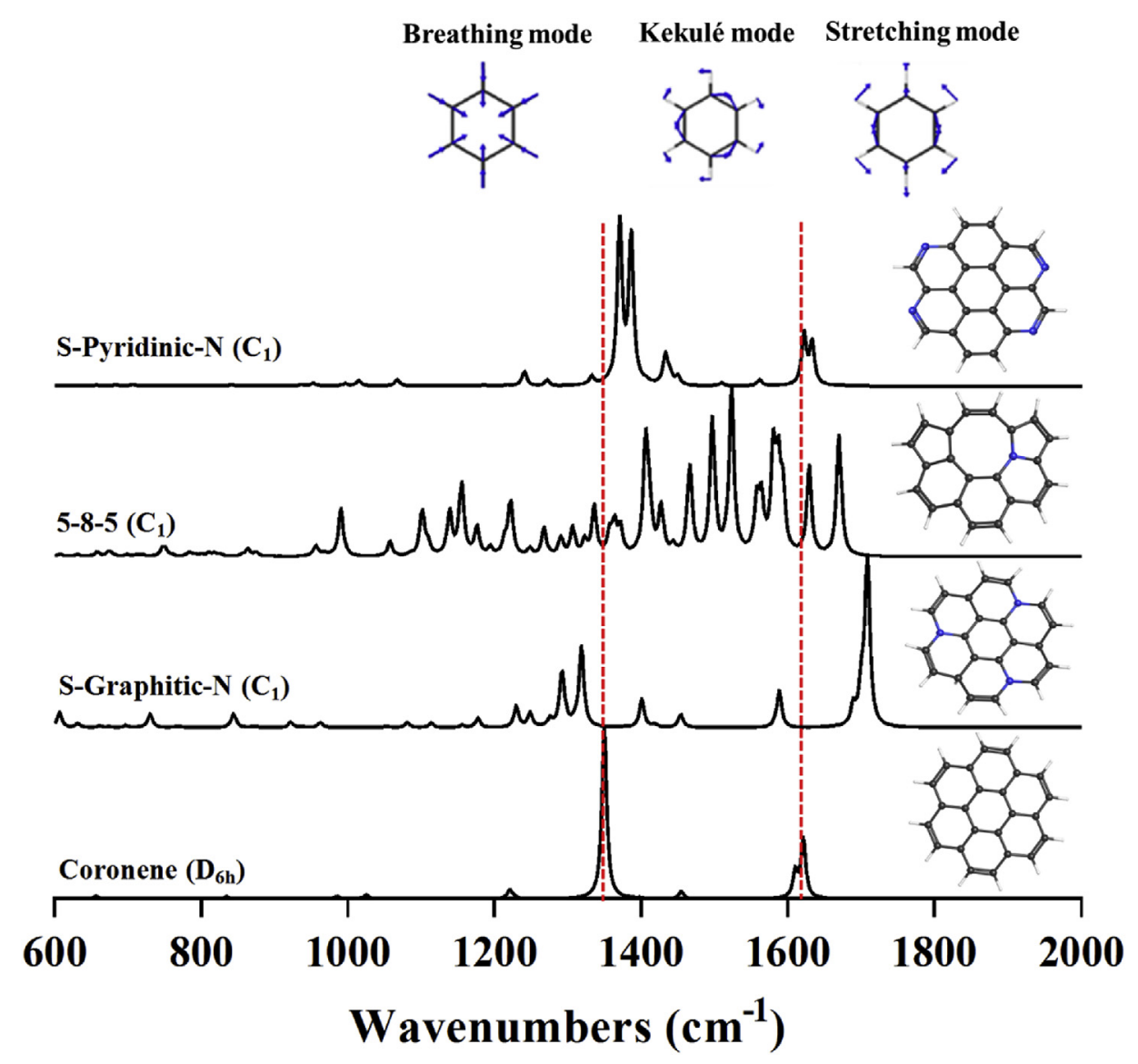

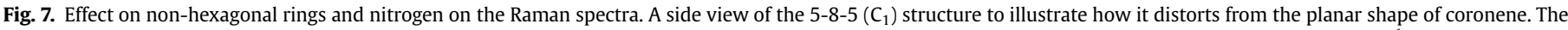

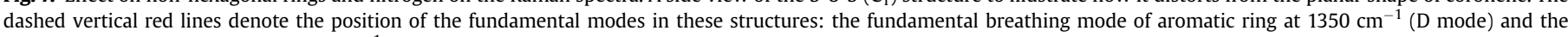

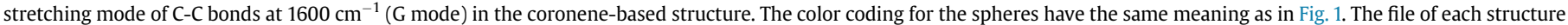
and the procedure to view the displacement of the atoms for each individual structure can be found in the supplementary data (Figs. S1, S2, S3, S4 and Table S1).

$\mathrm{N}$-doped char is presented as follows; the carbon content increases from 62 to 82 wt\%, nitrogen content decreases from 24 to 11 wt\%, oxygen and hydrogen content decreases from 10 to $6 \mathrm{wt} \%$ and $4 \mathrm{wt} \%$ to $1 \mathrm{wt} \%$ respectively as the temperature increases from 350 to $700{ }^{\circ} \mathrm{C}$. It is obvious that the spectra of char without nitrogen doping shows a much lower relative intensity of the $\mathrm{D}$ band as compared to the $\mathrm{N}$-doped char. The incorporation of nitrogen groups in the char leads to more defects and disorder in the structure. The transformation of the char from lower to higher temperatures leaves behind topological defects and vacancies or non-hexagonal rings systems. Studies show that nitrogen within a single point defect is capable of healing the structure by forming a non-hexagonal ring system [77-79].

As the production temperature varies from 350 to $700{ }^{\circ} \mathrm{C}$, there is a decrease in the intensity in the valley region between the $\mathrm{D}$ and the $G$ band (Valley). This phenomenon is due to the decrease in both nitrogen and oxygen functional groups in the char, which is suggestive of an increasing degree of graphitization along the annealing pathway. This result substantiates previous findings in the literature $[55,59]$. N-doping significantly enhances the defect density of the char as appreciated by the strong $\mathrm{D}$ band and high intensity between the D and $G$ band. Nitrogen functional groups strongly affect the vibrational modes in the valley region (see Fig. 10). This region has long been controversial to academic researchers.

Now, based on the information gathered from the computational calculation, the $\mathrm{N}$-doped char spectra was deconvoluted into
9-11 peaks. The possible vibrational structures/features are highlighted in Table 5. The relative intensities of the vibrational modes obtained as a result of the deconvolution with respect to the carbonization temperature is shown in Fig. 12.

D band: It is observed from Fig. 12 that the $\mathrm{D}$ band relative intensity increases with increasing carbonization temperature. This trend observed is consistent with previous studies [55]. This increase in the intensity of the D band is a result of several factors such as the increase in the size of the polyaromatic cluster. Also, the $\mathrm{D}$ band is affected by edges, curvature and doping that are directly related to the thermal treatment. A particularly interesting artifact of the computational spectra is that for larger PAHs systems (see Fig. 8, $\mathbf{C}_{\mathbf{9 6}}$ ), breathing modes were present not only in the center ring, but in all coronene-like clusters about it as well. All these vibrations contribute to the $\mathrm{D}$ band formation and hence, high intensity as compared to smaller clusters.

G band: The fundamental $G$ mode increases in intensity with respect to the carbonization temperature. It is important to recall that the $G$ mode is attributed to the stretching of $s p^{2}$ carbons. Hence, this behavior is associated to the fact that there is an increase in the clusters size and more $s p^{2}$ carbons are available to vibrate. These results are consistent with other studies in the literature $[44,80,81]$. Additionally, the presence of nitrogen in single point defects is determined to be capable of inducing the formation of rings and therefore contributes to the stretching mode [79]. This formation of rings when nitrogen is present in a single point defect is also supported by work done by Ayiania et al. [72], 


\section{Breathing Kekulé Stretching mode mode mode}<smiles>C[C@H]1C(C)(C)[C@]2(C)[C@@H](C)[C@@]1(C)C2(C)C</smiles><smiles>CCC1(C)CC(C)(C)C(C)(C)CC1(C)C</smiles><smiles>CCC1C(C)C(C)C(CC)C(C)C1C</smiles>

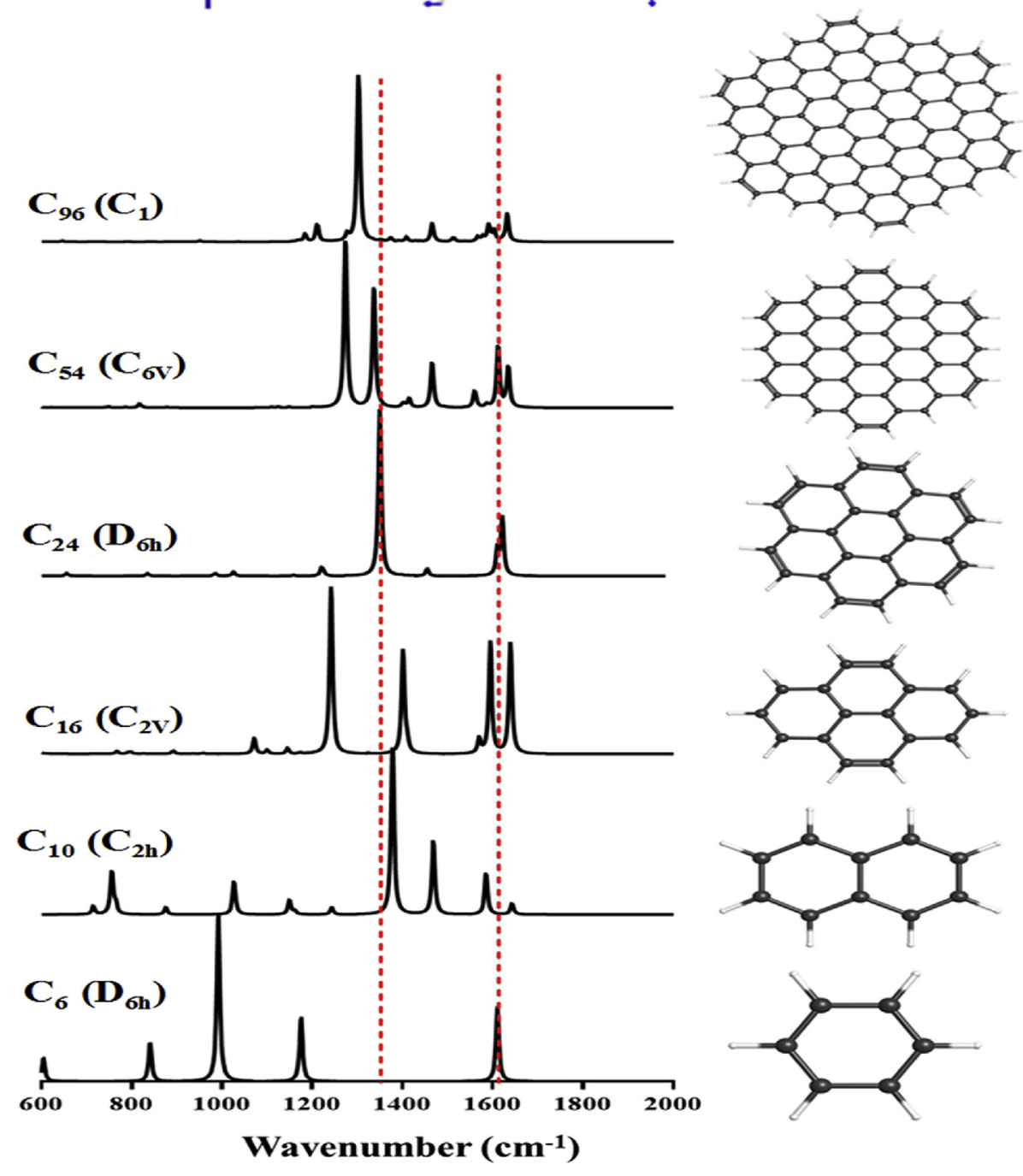

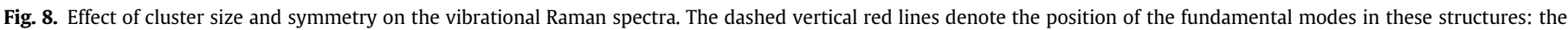

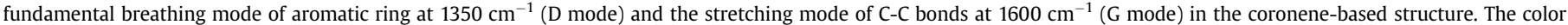

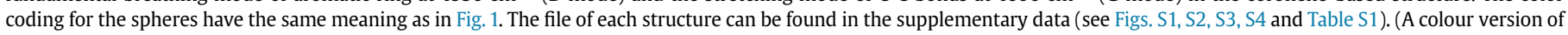
this figure can be viewed online.)

where they noticed that nitrogen in single point defects in a graphene sheet could induce a ring formation after optimization of the structure.

$A$ band: Between the $D$ and the $G$ band (the valley) lies the uncertainty, here referred to as $A_{1}$ and $A_{2}$. Based on the computational results, this region of the spectra results from assorted vibrations caused by the presence of heteroatoms (oxygen and nitrogen functional groups) such as graphitic nitrogen and ether groups within the vacant region, especially Kekule type vibrations. Graphitic nitrogen in PAHs system tend to be responsible for these vibrations (see Figs. 3 and 4). Also, both nitrogen and oxygen groups within the edges of single point defects (see Fig. 6) lead to a complex spectrum within those regions. These vibrations decrease in intensity as a result of the loss of both nitrogen and oxygen functional groups as the carbonization temperature increases from 350 to $700{ }^{\circ} \mathrm{C}$ (see Fig. 12). When comparing the Raman spectra of $\mathrm{N}$ doped char to char without $\mathrm{N}$-doping, the valley region of the $\mathrm{N}$ doped char is much more intense due to the high nitrogen content (See Fig. 10). Another substantial factor of this region is also characterized by the presence of non-hexagonal rings systems (see Fig. 7). This study is in agreement with previous findings [55,59,82,83].

$D^{\prime}$ band: The D' (1605-1680 $\left.\mathrm{cm}^{-1}\right)$ peak remains practically constant over the carbonization temperature range (see Fig. 12). This peak is normally referred to as the defect induced peak associated with disorder in graphene like samples. Our computational 
Table 4

Summary of the vibrational features observed in Fig. 8.

\begin{tabular}{|c|c|c|c|c|c|}
\hline $\begin{array}{ll}975- & 1150 \\
1075 \mathrm{~cm}^{-1}-1200 \mathrm{~cm}^{-1}\end{array}$ & $\begin{array}{l}1250- \\
1320 \mathrm{~cm}^{-1}\end{array}$ & $\begin{array}{l}1330- \\
1380 \mathrm{~cm}^{-1}\end{array}$ & $\begin{array}{l}1400- \\
1460 \mathrm{~cm}^{-1}\end{array}$ & $\begin{array}{l}1480- \\
1550 \mathrm{~cm}^{-1}\end{array}$ & $1570-1600 \mathrm{~cm}^{-1}$ \\
\hline $\begin{array}{l}\mathrm{A}_{1 \mathrm{~g}} \text { breathing of structure } \\
\text { Fundamental breathing } \\
\text { mode of smaller PAHs } \\
\text { such as benzene and } \\
\text { secondary breathing } \\
\text { of naphthalene }\left(\mathrm{C}_{6^{-}}\right. \\
\left.\mathrm{C}_{10}\right) \text {. }\end{array}$ & $\begin{array}{l}\text { The fundamental breathing of } \\
\text { small molecules like pyrene } \\
\left(C_{16}\right) \text {. } \\
\text { Breathing of pyrene and coror } \\
\text { larger PAHs }\left(C_{54} \text { and } C_{96}\right) \text { or } g\end{array}$ & $\begin{array}{l}\text { The fundamental center } \\
\text { breathing mode of most PAHs } \\
\text { systems. } \\
\text { nene-like moieties within a } \\
\text { reater. }\end{array}$ & $\begin{array}{l}A_{1 g} \text { breathing/Kekulé } \\
A_{\text {lg }} \text { fundamental breathing mode of } \\
\text { smaller system like naphthalene and } \\
\text { pyrene }\left(C_{10}-C_{16}\right) \text {. } \\
\text { Kekule vibration in PAHs. However, tl } \\
\text { are weak for larger system. Assorted v } \\
\text { seen for larger systems. This region on } \\
\text { vibration in the presence of heteroato }\end{array}$ & $\begin{array}{l}\text { e vibrations } \\
\text { tions can be } \\
\text { hows strong } \\
\text { and defects. }\end{array}$ & $\begin{array}{l}\mathrm{E}_{2 \mathrm{~g}} s p^{2} \mathrm{C} \\
\text { Fundamental vibrational } \\
\text { stretching modes of all } s p^{2} \\
\text { carbon. } \\
\end{array}$ \\
\hline
\end{tabular}

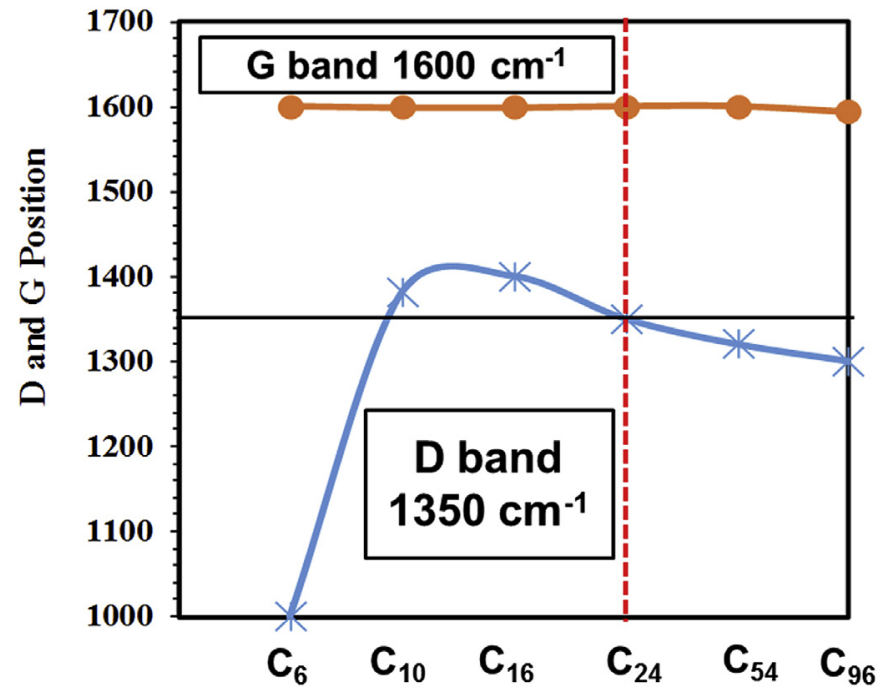

Fig. 9. Peak position of both $\mathrm{D}$ and $\mathrm{G}$ band with respect to different cluster sizes. The vertical red line shows the reference model "Coronene $\left(C_{24}\right)$ ". (A colour version of this figure can be viewed online.) studies reveal that incorporation of nitrogen groups result in assorted vibrations within that region. These vibrations are practically attributed to the center breathing mode and the stretching of the $\mathrm{C}-\mathrm{C}$ bonds as a result of the presence of foreign atoms which causes a compression stress on the structure [82]. This is particularly significant in the case of graphitic nitrogen and pyrrolic groups attached to an aromatic cluster (see Figs. 3,4 and 7). Our previous work on the thermodynamic stability nitrogen functionalities suggests pyrrolic and graphitic nitrogen to be very stable over a large range of temperature [72], hence, the presence of these functional groups might be responsible for the vibrational features is that region.

C band: The $C$ peaks $\left(1750-1800 \mathrm{~cm}^{-1}\right.$ ) refers to vibrations of the carbonyl group (see Fig. 6). This peak decreases as the pyrolysis temperature increases due to the loss of oxygen functional groups. In Fig. 11, notice that this peak can be seen at all temperatures except at $700{ }^{\circ} \mathrm{C}$ (this is supported by FTIR results, but not shown here). Is more prominent at $350^{\circ} \mathrm{C}$ due to the fact that the char still presents most of the components of the raw material and a high content of oxygen functionalities.

$D_{s}$ band: The $D_{s}\left(1250-1320 \mathrm{~cm}^{-1}\right)$ region is characterized by the fundamental breathing of small molecules like pyrene $\left(\mathrm{C}_{16}\right)$ as well as the assorted frustrated breathing modes of the whole PAHs due to the presence of heteroatoms, and secondary breathing of larger

Table 5

Summary of peak assignment.

\begin{tabular}{|c|c|c|}
\hline $\begin{array}{l}\text { Position } \\
\left(\mathrm{cm}^{-1}\right)\end{array}$ & Peak & Assignment \\
\hline 900-1075 & $S_{L}$ & $\begin{array}{l}\text { - Fundamental breathing mode of smaller PAHs such as Benzene and secondary breathing of Naphthalene. }\left(\mathrm{C}_{6}-\mathrm{C}_{10}\right) \\
\text { - Secondary Kekulé mode of larger PAHs cross linked to smaller PAH moieties. }\end{array}$ \\
\hline $1150-1200$ & $\mathrm{~S}$ & $\begin{array}{l}\text { - Frustrated breathing of mode of larger PAHs regions contain graphitic nitrogen. } \\
\text { - Secondary breathing of seven or more membered ring connected to a graphitic nitrogen. }\end{array}$ \\
\hline $1250-1300$ & $\mathrm{D}_{\mathrm{S}}$ & $\begin{array}{l}\text { - The fundamental breathing of small molecules like pyrene }\left(C_{16}\right) \\
\text { - Breathing of pyrene-like moieties within a larger PAHs } C_{54} \text {. } \\
\text { - Assorted frustrated breathing modes of the whole PAHs due to the presence of heteroatoms. } \\
\text { - Secondary breathing of larger non hexagonal rings containing heteroatoms. }\end{array}$ \\
\hline $1340-1380$ & $\mathrm{D}$ & $\begin{array}{l}\text { - This is the fundamental frequency for most PAHs with defects, grain size, vacancies, heteroatoms. } \\
\text { - Breathing coronene-like moieties within a larger PAHs }\left(C_{96}\right) \text {. } \\
\text { - Center breathing modes combined with Kekulé modes found in rings at the peripheral in PAHs. } \\
\text { - However, } A_{\lg } \text { fundamental breathing mode of smaller system like naphthalene and pyrene }\left(C_{10}-C_{16}\right) \text { is shifted to } 1400 \mathrm{~cm}^{-1} \text {. }\end{array}$ \\
\hline $1400-1460$ & $A_{1}$ & $\begin{array}{l}\text { - Alg fundamental breathing mode of smaller system like naphthalene and pyrene }\left(C_{10}-C_{16}\right) \\
\text { - Breathing modes of } 5 \text { membered ring structures. } \\
\text { - Secondary Kekulé vibration in PAHs. However, these vibrations are weak for larger systems. } \\
\text { - Assorted vibrations can be seen for larger systems. This region only shows strong vibration in the presence of heteroatoms and defects }\end{array}$ \\
\hline $1480-1550$ & $\mathrm{~A}_{2}$ & - Combined breathing, Kekulé and stretching of different moieties in PAHs mainly caused by the presence of nitrogen and oxygen functional groups. \\
\hline $1570-1600$ & $\mathrm{G}_{\mathrm{G}}$ & - Fundamental asymmetric/symmetric stretching mode of PAHs in both small and larger clusters. \\
\hline $1605-1650$ & $\mathrm{D}^{\prime}$ & $\begin{array}{l}\text { - Assorted vibrations in this region is a signature of the presence of heteroatoms due to doping or impurities as well as the presence of carbons with } \\
s p^{3} \text { character. }\end{array}$ \\
\hline $1750-1800$ & $\mathrm{C}$ & - Carbonyl stretching mode, weak. \\
\hline
\end{tabular}




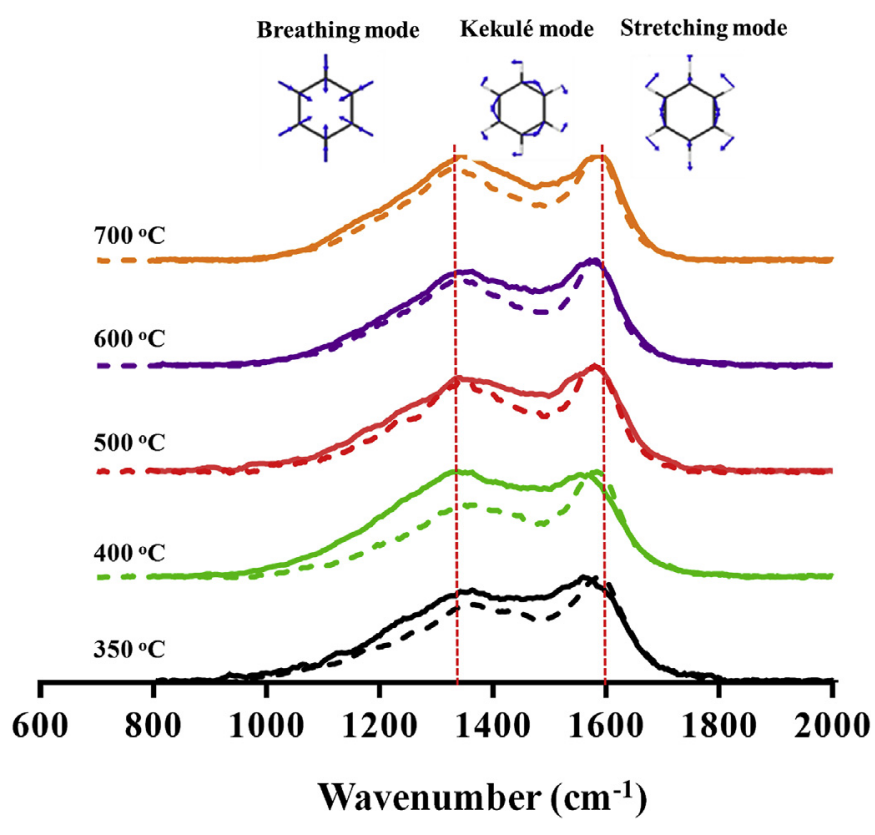

Fig. 10. Normalized Raman spectra of char N-doped (solid line) and non-doped char (dash lines). The dashed vertical red lines denote the position of the fundamental modes in these structures: the fundamental breathing mode of aromatic ring at $1350 \mathrm{~cm}^{-1}$ (D mode) and the stretching mode of C-C bonds at $1600 \mathrm{~cm}^{-1}$ ( $\mathrm{G}$ mode) in the coronene-based structure. (A colour version of this figure can be viewed online.) non-hexagonal rings containing heteroatoms $(6+$ rings). The vibrational intensities of the structures decrease as the production temperatures increases due to the formation of larger clusters and cross-linked structures of other PAHs. Also, most functional groups are lost leaving the skeletal carbon structure.

$S_{L}$ band: For $S_{L}$ and $S\left(900-1075\right.$ and $1150-1200 \mathrm{~cm}^{-1}$ ), these regions are mostly characterized by the fundamental breathing of the smaller PAHs such as benzene and secondary breathing of naphthalene $\left(\mathrm{C}_{6}-\mathrm{C}_{12}\right)$ (see Figs. 2 and 8 ). It is logical that the peak intensity of these structures decreases with respect temperature as the most of these structures grow into larger clusters.

Peak Position: The increasing carbonization temperature causes the $\mathrm{D}$ band positions for the $\mathrm{N}$-doped chars to redshift over the range of $350-700{ }^{\circ} \mathrm{C}$ (see Fig. 12). This observation has been suggested in the literature as an increase in the aromatic clusters (and/ or graphene-like domains) within carbonized chars. Similar observations were noticed in others studies $[58,81]$. These remarks agree well with our calculations shown in Fig. 8. In contrast, the Gband positions shifted gradually to higher wavenumbers with respect to the carbonization temperatures. A similar trend is also observed for the A band. McDonald-Wharry et al. attributed this blueshift to be caused by an increasing compressive strain exerted as the clusters grow large enough to collide or merge with nearby clusters within a confined volume [82]. This deduction was further supported by a different study where a compressive strain was exerted on graphite, a blueshift in the $G$ band was observed after the experiment $[84,85]$. The introduction of nitrogen groups also activate peaks in the region between 1605 and $1650 \mathrm{~cm}^{-1}$. This might be partly the reason behind the broad nature of the $G$ band as it consists of assorted vibrations which can best be described with
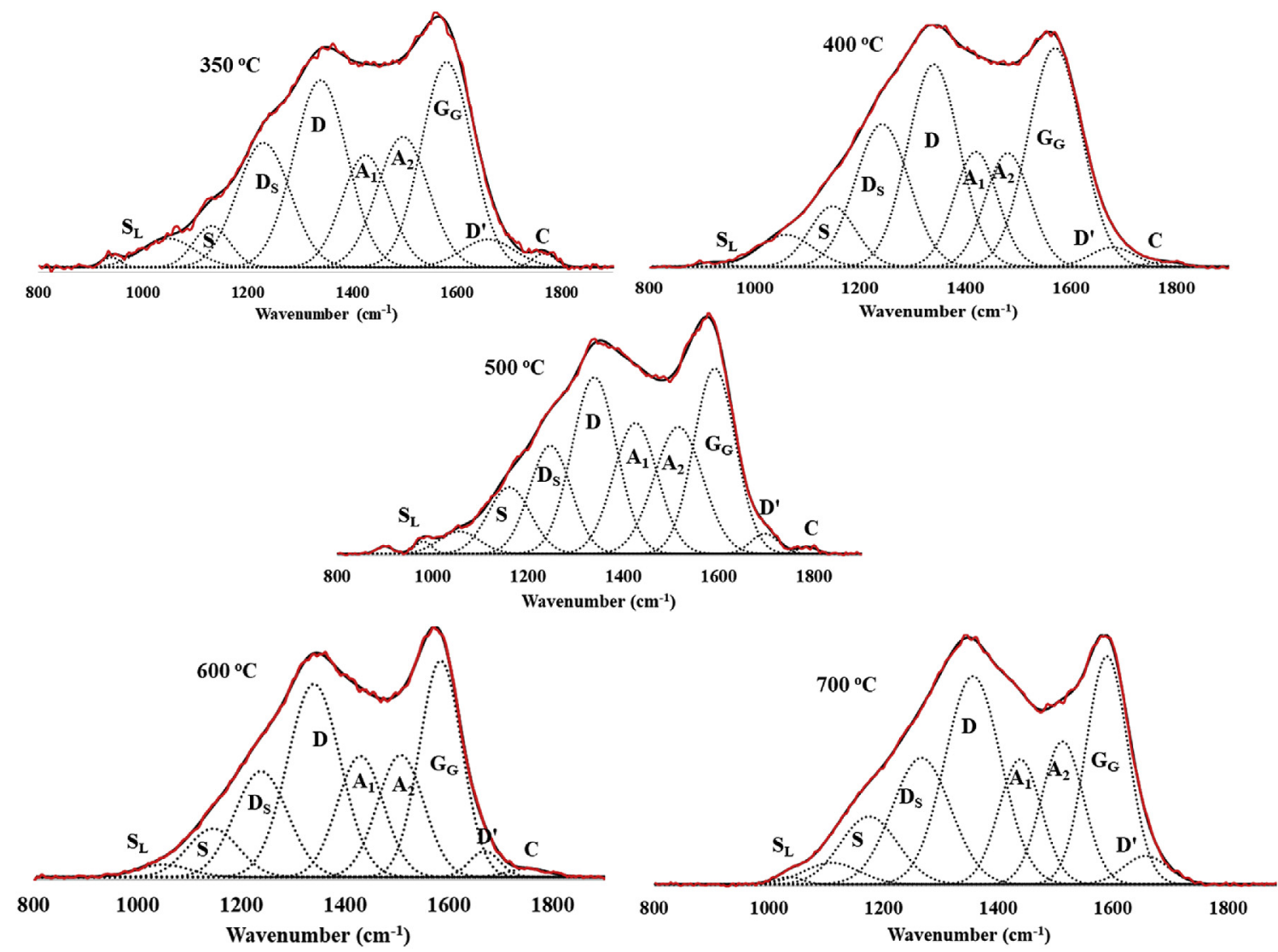

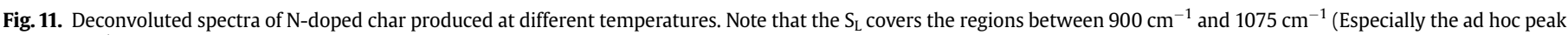
at $900 \mathrm{~cm}^{-1}$ in the $500{ }^{\circ} \mathrm{C}$ biochar is part of the $S_{\mathrm{L}}$ peak). (A colour version of this figure can be viewed online.) 

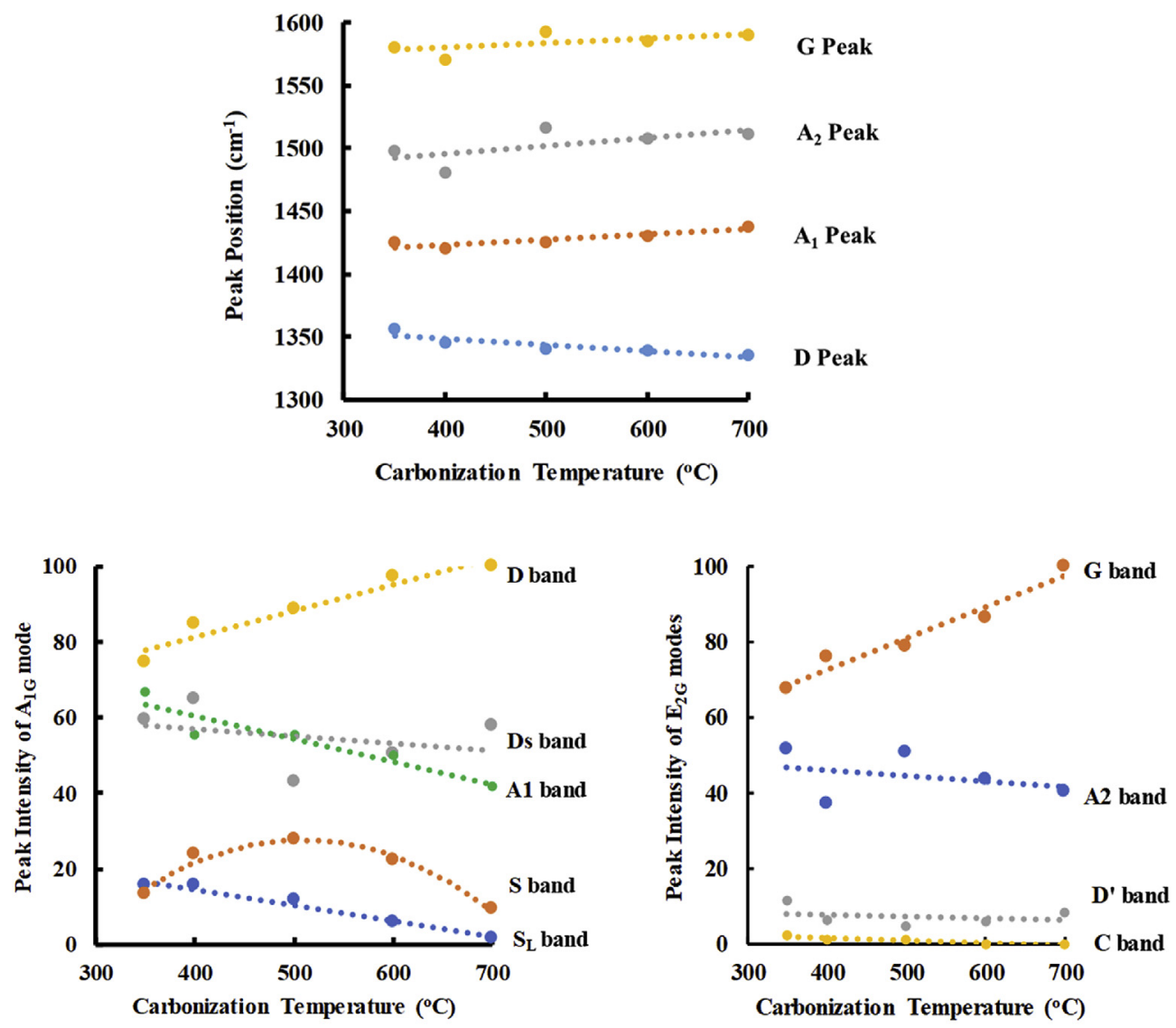

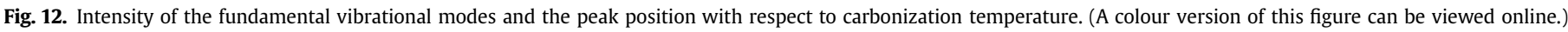

gaussians functions. More results on the peak positions and the peak width after the deconvolution are shown in the SI.

\section{Conclusion}

Gas phase Raman spectra of different nitrogenated structures were generated via DFT-based calculations, where we evaluated the effect of heteroatoms (nitrogen and oxygen) on the corresponding vibrational spectra. Defects have an important effect on the Raman spectra due to symmetry effect. Heteroatoms contribute or induces the active vibrations in the region between 1400 and $1550 \mathrm{~cm}^{-1}$. We also observed from the computational results that both oxygen and nitrogen within single- and double-point defect are responsible for the intensity in the valley region. Also, the shoulder region of the D band between 1250 and $1320 \mathrm{~cm}^{-1}$ is fundamentally associated with the breathing mode of defective PAHs. However, these vibrations are intense in the presence of functional groups like graphitic nitrogen.

The breathing of an 8-membered ring with nitrogen in the ring happen on the shoulder of the D band between 1150 and $1200 \mathrm{~cm}^{-1}$. Furthermore, lower vibrational wavenumbers (800$1075 \mathrm{~cm}^{-1}$ ) are attributed to smaller PAHs in the range of $C_{6}-C_{16}$ either individually or cross-linked to larger systems. Higher vibrational wavenumbers from 1600 to $1680 \mathrm{~cm}^{-1}$ are a result of the assorted breathing mode and stretching of the $\mathrm{C}-\mathrm{C}$ bond which is associated to structures containing 5-membered rings with nitrogen (a pyrrole group) and the structures containing graphitic nitrogen. Nitrogen functional groups at the edge of a PAHs such as pyridine, amine, and amide do not have significant effect on the spectra.

The deconvolution of the Raman spectra of chars obtained at different temperatures shows changes in the position of $\mathrm{D}$ band due to the increase in size of the aromatic cluster. In contrast, the $G$ band's peak position slightly increases. The relative intensities of the most prominent peaks ( $D$ and $G$ band) increases with carbonization temperatures also confirming growth of the aromatic cluster and graphitization. The principal contributors to the A band region (the valley) are the point vacancies, ring structures with more than 6 carbons, and heteroatom $(\mathrm{O}$ and $\mathrm{N})$ defects.

\section{CRediT authorship contribution statement}

Michael Ayiania: Conceptualization, Methodology, Software, Validation, Formal analysis, Investigation, Writing - original draft, Writing - review \& editing, Visualization. Elsa Weiss-Hortala: Methodology, Software, Validation, Writing - review \& editing. Matthew Smith: Methodology, Software, Validation, Formal analysis, Writing - review \& editing. Jean-Sabin McEwen: Conceptualization, Methodology, Resources, Data curation, Writing - review \& editing, Supervision, Project administration, Funding acquisition. Manuel Garcia-Perez: Conceptualization, Resources, Writing - review \& editing, Supervision, Project administration, Funding acquisition.

\section{Declaration of competing interest}

The authors declare that they have no known competing financial interests or personal relationships that could have 
appeared to influence the work reported in this paper.

\section{Acknowledgements}

This work was supported by the National Science Foundation under Contract No. CBET-1703052. The authors thank Aidan Garcia, Dr. Alyssa J. R. Hensley, Kyle Groden, Sohrab Haghighi Mood and Yaime Jefferson Milan and Jonathan Kojo for their helpful comments and discussions. Dr. Garcia-Perez would like to thank the Washington State Applied Bioenergy program (Appendix A) and the Sun Grant Initiative (Federal USDA/NIFA award: 2014-3850222598) for the financial support provided. Dr Elsa Weiss-Hortala would like to thank Laurène Haurie for her support in Raman spectra acquisition. This research used resources from the Center for Institutional Research Computing at Washington State University. This work was partially funded by the Joint Center for Deployment and Research in Earth Abundant Materials (JCDREAM) in Washington State. PNNL is a multiprogram national laboratory operated for the US DOE by Battelle.

\section{Appendix A. Supplementary data}

Supplementary data to this article can be found online at https://doi.org/10.1016/j.carbon.2020.05.055.

\section{References}

[1] M. Dresselhaus, G. Dresselhaus, Intercalation compounds of graphite, Adv. Phys. 30 (1981) 139-326.

[2] G. Duesberg, A. Graham, F. Kreupl, M. Liebau, R. Seidel, E. Unger, et al., Ways towards the scaleable integration of carbon nanotubes into silicon based technology, Diam. Relat. Mater. 13 (2004) 354-361.

[3] J.C. Tsang, M. Freitag, V. Perebeinos, J. Liu, P. Avouris, Doping and phonon renormalization in carbon nanotubes, Nat. Nanotechnol. 2 (2007) 725-730.

[4] H.P. Boehm, Chemical Identification of Surface Groups. Adv. Catal., Elsevier, 1966, pp. 179-274.

[5] L. Li, P.A. Quinlivan, D.R. Knappe, Effects of activated carbon surface chemistry and pore structure on the adsorption of organic contaminants from aqueous solution, Carbon 40 (2002) 2085-2100.

[6] M. Montes-Morán, D. Suárez, J. Menéndez, E. Fuente, On the nature of basic sites on carbon surfaces: an overview, Carbon 42 (2004) 1219-1225.

[7] T.J. Bandosz, C. Ania, Surface chemistry of activated carbons and its characterization, Interface Sci.Technol. (2006) 159-229.

[8] E. Cruz-Silva, Z. Barnett, B.G. Sumpter, V. Meunier, Structural, magnetic, and transport properties of substitutionally doped graphene nanoribbons from first principles, Phys. Rev. B 83 (2011) 155445.

[9] Y. Wang, Y. Shao, D.W. Matson, J. Li, Y. Lin, Nitrogen-doped graphene and its application in electrochemical biosensing. ACS Nano 4 (2010) 1790-1798.

[10] Y. Shao, J. Sui, G. Yin, Y. Gao, Nitrogen-doped carbon nanostructures and their composites as catalytic materials for proton exchange membrane fuel cell, Appl. Catal. B Environ. 79 (2008) 89-99.

[11] R. Lv, M. Terrones, Towards new graphene materials: doped graphene sheets and nanoribbons, Mater. Lett. 78 (2012) 209-218.

[12] R. Lv, Q. Li, A.R. Botello-Méndez, T. Hayashi, B. Wang, A. Berkdemir, et al., Nitrogen-doped graphene: beyond single substitution and enhanced molec ular sensing, Sci. Rep. 2 (2012) 586.

[13] A.L.M. Reddy, A. Srivastava, S.R. Gowda, H. Gullapalli, M. Dubey, P.M. Ajayan, Synthesis of nitrogen-doped graphene films for lithium battery application, ACS Nano 4 (2010) 6337-6342.

[14] H. Wang, C. Zhang, Z. Liu, L. Wang, P. Han, H. Xu, et al., Nitrogen-doped graphene nanosheets with excellent lithium storage properties, J. Mater. Chem. 21 (2011) 5430-5434.

[15] D. Yu, E. Nagelli, F. Du, L. Dai, Metal-free carbon nanomaterials become more active than metal catalysts and last longer, J. Phys. Chem. Lett. 1 (2010) 2165-2173.

[16] J.-i. Ozaki, Simultaneous doping of boron and nitrogen into a carbon to enhance its oxygen reduction activity in proton exchange membrane fue cells, Carbon 44 (2006) 3358

[17] L. Zhang, J. Zhang, D.P. Wilkinson, H. Wang, Progress in preparation of nonnoble electrocatalysts for PEM fuel cell reactions, J. Power Sources 156 (2006) 171-182.

[18] M. Lefèvre, E. Proietti, F. Jaouen, J.-P. Dodelet, Iron-based catalysts with improved oxygen reduction activity in polymer electrolyte fuel cells, Science 324 (2009) 71-74.

[19] G. Wu, K.L. More, C.M. Johnston, P. Zelenay, High-performance electrocatalysts for oxygen reduction derived from polyaniline, iron, and cobalt,
Science 332 (2011) 443-447.

[20] E. Proietti, F. Jaouen, M. Lefèvre, N. Larouche, J. Tian, J. Herranz, et al., Ironbased cathode catalyst with enhanced power density in polymer electrolyte membrane fuel cells, Nat. Commun. 2 (2011) 416.

[21] D.H. Lee, W.J. Lee, W.J. Lee, S.O. Kim, Y.-H. Kim, Theory, synthesis, and oxygen reduction catalysis of Fe-porphyrin-like carbon nanotube, Phys. Rev. Lett. 106 (2011) 175502

[22] D. Deng, X. Pan, L. Yu, Y. Cui, Y. Jiang, J. Qi, et al., Toward N-doped graphene via solvothermal synthesis, Chem. Mater. 23 (2011) 1188-1193.

[23] R.I. Jafri, N. Rajalakshmi, S. Ramaprabhu, Nitrogen doped graphene nanoplatelets as catalyst support for oxygen reduction reaction in proton exchange membrane fuel cell, J. Mater. Chem. 20 (2010) 7114-7117.

[24] Y.-H. Lu, M. Zhou, C. Zhang, Y.-P. Feng, Metal-embedded graphene: a possible catalyst with high activity, J. Phys. Chem. C 113 (2009) 20156-20160.

[25] Y. Li, J. Wang, X. Li, J. Liu, D. Geng, J. Yang, et al., Nitrogen-doped carbon nanotubes as cathode for lithium-air batteries, Electrochem. Commun. 13 (2011) 668-672.

[26] H. Xu, D. Cheng, D. Cao, X.C. Zeng, A universal principle for a rational design of single-atom electrocatalysts, Nat. Catal. 10 (2018).

[27] X. Wang, Y. Qin, L. Zhu, H. Tang, Nitrogen-doped reduced graphene oxide as a bifunctional material for removing bisphenols: synergistic effect between adsorption and catalysis, Environ. Sci. Technol. 49 (2015) 6855-6864.

[28] Y. Liu, L. Yu, C.N. Ong, J. Xie, Nitrogen-doped graphene nanosheets as reactive water purification membranes, Nano Res. 9 (2016) 1983-1993.

[29] P. Malik, Dye removal from wastewater using activated carbon developed from sawdust: adsorption equilibrium and kinetics, J. Hazard Mater. 113 (2004) 81-88.

[30] K. Kadirvelu, M. Kavipriya, C. Karthika, M. Radhika, N. Vennilamani, S. Pattabhi, Utilization of various agricultural wastes for activated carbon preparation and application for the removal of dyes and metal ions from aqueous solutions, Bioresour. Technol. 87 (2003) 129-132.

[31] X. Wang, N. Zhu, B. Yin, Preparation of sludge-based activated carbon and its application in dye wastewater treatment, J. Hazard Mater. 153 (2008) 22-27.

[32] S. Babel, T.A. Kurniawan, Cr (VI) removal from synthetic wastewater using coconut shell charcoal and commercial activated carbon modified with oxidizing agents and/or chitosan, Chemosphere 54 (2004) 951-967.

[33] X. Hu, L. Lei, H.P. Chu, P.L. Yue, Copper/activated carbon as catalyst for organic wastewater treatment, Carbon 37 (1999) 631-637.

[34] A. Ban, A. Schafer, H. Wendt, Fundamentals of electrosorption on activated carbon for wastewater treatment of industrial effluents, J. Appl. Electrochem. 28 (1998) 227-236.

[35] S.H. Mood, M. Ayiania, Y. Jefferson-Milan, M. Garcia-Perez, Nitrogen doped char from anaerobically digested fiber for phosphate removal in aqueous solutions, Chemosphere 240 (2019) 124889.

[36] R.V. Siriwardane, M.-S. Shen, E.P. Fisher, J.A. Poston, Adsorption of CO2 on molecular sieves and activated carbon, Energy Fuels 15 (2001) 279-284.

[37] H. Tamon, M. Okazaki, Influence of acidic surface oxides of activated carbon on gas adsorption characteristics, Carbon 34 (1996) 741-746.

[38] R. Reich, W.T. Ziegler, K.A. Rogers, Adsorption of methane, ethane, and ethylene gases and their binary and ternary mixtures and carbon dioxide on activated carbon at 212-301 K and pressures to 35 atmospheres, Ind. Eng. Chem. 19 (1980) 336-344.

[39] E. Costa, J. Sotelo, G. Calleja, C. Marron, Adsorption of binary and ternary hydrocarbon gas mixtures on activated carbon: experimental determination and theoretical prediction of the ternary equilibrium data, AIChE J. 27 (1981) $5-12$.

[40] M. Ayiania, F.M. Carbajal-Gamarra, T. Garcia-Perez, C. Frear, W. Suliman, M. Garcia-Perez, Production and characterization of $\mathrm{H}_{2} \mathrm{~S}$ and $\mathrm{PO}^{3-}$ carbonaceous adsorbents from anaerobic digested fibers, Biomass Bioenergy 120 (2019) 339-349.

[41] A. Bagreev, D.C. Locke, T.J. Bandosz, H2S adsorption/oxidation on adsorbents obtained from pyrolysis of sewage-sludge-derived fertilizer using zinc chloride activation, Ind. Eng. Chem. Res. 40 (2001) 3502-3510.

[42] M.J. Antal, M. Grønli, The art, science, and technology of charcoal production, Ind. Eng. Chem. Res. 42 (2003) 1619-1640.

[43] G.M. Jenkins, K. Kawamura, Polymeric Carbons: Carbon Fibre, Glass and Char, Cambridge University Press, 1976.

[44] Y.-R. Rhim, D. Zhang, D.H. Fairbrother, K.A. Wepasnick, K.J. Livi, R.J. Bodnar, et al., Changes in electrical and microstructural properties of microcrystalline cellulose as function of carbonization temperature, Carbon 48 (2010) 1012-1024.

[45] G. Zickler, T. Schöberl, O. Paris, Mechanical properties of pyrolysed wood: a nanoindentation study, Philos. Mag. A 86 (2006) 1373-1386.

[46] S.-F. Huang, K. Terakura, T. Ozaki, T. Ikeda, M. Boero, M. Oshima, et al., Firstprinciples calculation of the electronic properties of graphene clusters doped with nitrogen and boron: analysis of catalytic activity for the oxygen reduction reaction, Phys. Rev. B 80 (2009) 235410.

[47] B. Biel, X. Blase, F. Triozon, S. Roche, Anomalous doping effects on charge transport in graphene nanoribbons, Phys. Rev. Lett. 102 (2009), 096803.

[48] Y. Shao, S. Zhang, M.H. Engelhard, G. Li, G. Shao, Y. Wang, et al., Nitrogendoped graphene and its electrochemical applications, J. Mater. Chem. 20 (2010) 7491-7496.

[49] X. Wang, X. Li, L. Zhang, Y. Yoon, P.K. Weber, H. Wang, et al., N-doping of graphene through electrothermal reactions with ammonia, Science 324 (2009) 768-771. 
[50] A.C. Ferrari, Raman spectroscopy of graphene and graphite: disorder, electron-phonon coupling, doping and nonadiabatic effects, Solid State Commun. 143 (2007) 47-57.

[51] A. Eckmann, A. Felten, A. Mishchenko, L. Britnell, R. Krupke, K.S. Novoselov, et al., Probing the nature of defects in graphene by Raman spectroscopy, Nano Lett. 12 (2012) 3925-3930.

[52] L. Cancado, M. Pimenta, B. Neves, M. Dantas, A. Jorio, Influence of the atomic structure on the Raman spectra of graphite edges, Phys. Rev. Lett. 93 (2004) 247401.

[53] J. Zabel, R.R. Nair, A. Ott, T. Georgiou, A.K. Geim, K.S. Novoselov, et al., Raman spectroscopy of graphene and bilayer under biaxial strain: bubbles and balloons, Nano Lett. 12 (2012) 617-621.

[54] T. Mohiuddin, A. Lombardo, R. Nair, A. Bonetti, G. Savini, R. Jalil, et al., Uniaxial strain in graphene by Raman spectroscopy: G peak splitting, Grüneisen parameters, and sample orientation, Phys. Rev. B 79 (2009) 205433.

[55] M.W. Smith, I. Dallmeyer, T.J Johnson, C.S. Brauer, J-S. McEwen, J.F. Espinal, et al., Structural analysis of char by Raman spectroscopy: improving band assignments through computational calculations from first principles, Carbon 100 (2016) 678-692.

[56] G.A. Zickler, B. Smarsly, N. Gierlinger, H. Peterlik, O. Paris, A reconsideration of the relationship between the crystallite size La of carbons determined by Xray diffraction and Raman spectroscopy, Carbon 44 (2006) 3239-3246.

[57] S. Gupta, A. Saxena, Nanocarbon materials: probing the curvature and topology effects using phonon spectra, J. Raman Spectrosc. 40 (2009) 1127-1137.

[58] S. Yamauchi, Y. Kurimoto, Raman spectroscopic study on pyrolyzed wood and bark of Japanese cedar: temperature dependence of Raman parameters, J. Wood Sci. 49 (2003) 235-240.

[59] C. Hu, S. Sedghi, A. Silvestre-Albero, G.G. Andersson, A. Sharma, P. Pendleton, et al., Raman spectroscopy study of the transformation of the carbonaceous skeleton of a polymer-based nanoporous carbon along the thermal annealing pathway, Carbon 85 (2015) 147-158.

[60] A.C. Ferrari, J. Robertson, Interpretation of Raman spectra of disordered and amorphous carbon, Phys, Rev, B 61 (2000) 14095.

[61] Z. Wang, A.G. McDonald, R.J. Westerhof, S.R. Kersten, C.M. Cuba-Torres, S. Ha, et al., Effect of cellulose crystallinity on the formation of a liquid intermediate and on product distribution during pyrolysis, J. Anal. Appl. Pyrolysis 100 (2013) 56-66.

[62] M. Smith, L. Scudiero, J. Espinal, J.-S. McEwen, M. Garcia-Perez, Improving the deconvolution and interpretation of XPS spectra from chars by ab initio calculations, Carbon 110 (2016) 155-171.

[63] Y. Kawashima, G. Katagiri, Fundamentals, overtones, and combinations in the Raman spectrum of graphite, Phys. Rev. B 52 (1995) 10053.

[64] J. Schmidt, W. Polik, WebMO Enterprise, Version 13.0, WebMO LLC, 2013.

[65] M.D. Halls, J. Velkovski, H.B. Schlegel, Harmonic frequency scaling factors for Hartree-Fock, S-VWN, B-LYP, B3-LYP, B3-PW91 and MP2 with the Sadlej pVTZ electric property basis set, Theor. Chem. Acc. 105 (2001) 413-421.

[66] M. Pimenta, G. Dresselhaus, M.S. Dresselhaus, L. Cancado, A. Jorio, R. Saito, Studying disorder in graphite-based systems by Raman spectroscopy, Phys. Chem. Chem. Phys. 9 (2007) 1276-1290.

[67] O. Beyssac, B. Goffé, J.-P. Petitet, E. Froigneux, M. Moreau, J.-N. Rouzaud, On the characterization of disordered and heterogeneous carbonaceous materials by Raman spectroscopy, Spectrochim. Acta Mol. Biomol. Spectrosc. 59 (2003) 2267-2276.

[68] A.C. Ferrari, J. Robertson, Raman spectroscopy of amorphous, nanostructured, diamond-like carbon, and nanodiamond, Philos. Trans. R. Soc. Lond. Ser. B Biol. Sci. 362 (2004) 2477-2512.

[69] R. Beams, L.G. Cançado, L. Novotny, Raman characterization of defects and dopants in graphene, J. Phys. Condens. Matter 27 (2015), 083002.

[70] B. Guo, Q. Liu, E. Chen, H. Zhu, L. Fang, J.R. Gong, Controllable N-doping of graphene, Nano Lett. 10 (2010) 4975-4980.

[71] Y.-C. Lin, C.-Y. Lin, P.-W. Chiu, Controllable graphene N-doping with ammonia plasma, Appl. Phys. Lett. 96 (2010) 133110.

[72] M. Ayiania, A.J. Hensley, K. Groden, M. Garcia-Perez, J.-S. McEwen, Thermodynamic stability of nitrogen functionalities and defects in graphene and graphene nanoribbons from first principles, Carbon 152 (2019) 715-726.

[73] M. Ayiania, M. Smith, A.J.R. Hensley, L. Scudiero, J.-S. McEwen, M. GarciaPerez, Deconvoluting the XPS spectra for nitrogen-doped chars: An analysis from first principles, Carbon 162 (2020) 528-544.

[74] F. Negri, C. Castiglioni, M. Tommasini, G. Zerbi, A computational study of the Raman spectra of large polycyclic aromatic hydrocarbons: toward molecularly defined subunits of graphite, J. Phys. Chem. 106 (2002) 3306-3317.

[75] C.E. Brewer, K. Schmidt-Rohr, J.A. Satrio, R.C. Brown, Characterization of biochar from fast pyrolysis and gasification systems, Environ. Prog. Sustain. Energy 28 (2009) 386-396.

[76] X. Cao, J.J. Pignatello, Y. Li, C. Lattao, M.A. Chappell, N. Chen, et al., Characterization of wood chars produced at different temperatures using advanced solid-state 13C NMR spectroscopic techniques, Energy Fuels 26 (2012) 5983-5991.

[77] H.C. Schniepp, J.-L. Li, M.J. McAllister, H. Sai, M. Herrera-Alonso, D.H. Adamson, et al., Functionalized single graphene sheets derived from splitting graphite oxide, J. Phys. Chem. B 110 (2006) 8535-8539.

[78] M.J. McAllister, J.-L. Li, D.H. Adamson, H.C. Schniepp, A.A. Abdala, J. Liu, et al., Single sheet functionalized graphene by oxidation and thermal expansion of graphite, Chem. Mater. 19 (2007) 4396-4404.

[79] X.-F. Li, K.-Y. Lian, L Liu, Y. Wu, Q Oiu, J. Jiang et al, Unraveling the formation mechanism of graphitic nitrogen-doping in thermally treated graphene with ammonia, Sci. Rep. 6 (2016) 23495.

[80] M. Keiluweit, P.S. Nico, M.G. Johnson, M. Kleber, Dynamic molecular structure of plant biomass-derived black carbon (biochar), Environ. Sci. Technol. 44 (2010) 1247-1253.

[81] O. Paris, C. Zollfrank, G.A. Zickler, Decomposition and carbonisation of woor biopolymers - a microstructural study of softwood pyrolysis, Carbon 43 (2005) 53-66

[82] J. McDonald-Wharry, M. Manley-Harris, K. Pickering, Carbonisation of biomass-derived chars and the thermal reduction of a graphene oxide sample studied using Raman spectroscopy, Carbon 59 (2013) 383-405.

[83] P.J. Harris, Z. Liu, K. Suenaga, Imaging the atomic structure of activated carbon, J. Phys. Condens. Matter 20 (2008) 362201.

[84] E del Corro, A.O de la Roza, M. Taravillo, V.G. Baonza, Raman modes and Grüneisen parameters of graphite under compressive biaxial stress, Carbon 50 (2012) 4600-4606.

[85] M. Hanfland, H. Beister, K. Syassen, Graphite under pressure: equation of state and first-order Raman modes, Phys. Rev. B 39 (1989) 12598. 